\title{
An integrative genome-wide transcriptome reveals that candesartan is neuroprotective and a candidate therapeutic for Alzheimer's disease
}

\author{
Abdel G. Elkahloun ${ }^{1}$, Roman Hafko ${ }^{2}$ and Juan M. Saavedra ${ }^{2,3^{*}}$
}

\begin{abstract}
Background: Alzheimer's disease is the most frequent age-related dementia, and is currently without treatment. To identify possible targets for early therapeutic intervention we focused on glutamate excitotoxicity, a major early pathogenic factor, and the effects of candesartan, an angiotensin receptor blocker of neuroprotective efficacy in cell cultures and rodent models of Alzheimer's disease. The overall goal of the study was to determine whether gene analysis of drug effects in a primary neuronal culture correlate with alterations in gene expression in Alzheimer's disease, thus providing further preclinical evidence of beneficial therapeutic effects.

Methods: Primary neuronal cultures were treated with candesartan at neuroprotective concentrations followed by excitotoxic glutamate amounts. We performed genome-wide expression profile analysis and data evaluation by ingenuity pathway analysis and gene set enrichment analysis, compared with alterations in gene expression from two independent published datasets identified by microarray analysis of postmortem hippocampus from Alzheimer's disease patients. Preferential expression in cerebrovascular endothelial cells or neurons was analyzed by comparison to published gene expression in these cells isolated from human cortex by laser capture microdissection.

Results: Candesartan prevented glutamate upregulation or downregulation of several hundred genes in our cultures. Ingenuity pathway analysis and gene set enrichment analysis revealed that inflammation, cardiovascular disease and diabetes signal transduction pathways and amyloid $\beta$ metabolism were major components of the neuronal response to glutamate excitotoxicity. Further analysis showed associations of glutamate-induced changes in the expression of several hundred genes, normalized by candesartan, with similar alterations observed in hippocampus from Alzheimer's disease patients. Gene analysis of neurons and cerebrovascular endothelial cells obtained by laser capture microdissection revealed that genes up- and downregulated by glutamate were preferentially expressed in endothelial cells and neurons, respectively.

Conclusions: Our data may be interpreted as evidence of direct candesartan neuroprotection beyond its effects on blood pressure, revealing common and novel disease mechanisms that may underlie the in vitro gene alterations reported here and glutamate-induced cell injury in Alzheimer's disease. Our observations provide novel evidence for candesartan neuroprotection through early molecular mechanisms of injury in Alzheimer's disease, supporting testing this compound in controlled clinical studies in the early stages of the illness.
\end{abstract}

Keywords: Alzheimer's disease, Neurodegenerative disorders, Glutamate excitotoxicity, Neuroprotection, Angiotensin II receptor blockers, IPA analysis, GEO database, GSEA

\footnotetext{
* Correspondence: jms522@georgetown.edu

${ }^{3}$ Department of Pharmacology and Physiology, Georgetown University

Medical Center, SE402 Med/Dent, 3900 Reservoir Road, Washington, DC 20057, USA

Full list of author information is available at the end of the article
} 


\section{Background}

Alzheimer's disease is the most common age-related dementia and a major and increasing burden for our society [1]. This disorder is currently without treatment, and therapies to ameliorate alterations in amyloid beta $(A \beta)$ or tau metabolism, initiated too late in the disease course, have proven disappointing [2]. For this reason the search for early pathogenic mechanisms susceptible to therapeutic intervention is a medical necessity.

Emerging evidence indicates a role for multifactorial mechanisms involved in the early stages of the disease and preceding diagnosis. These mechanisms include genetic factors, possibly of cumulative impact [3], risk factors, such as cardiovascular disease and diabetes [4, 5], alterations in the microvasculature [4-6], chronic dysregulated inflammation $[6,7]$ and glutamate-mediated excitotoxicity [3, 8-10].

In the present report we focused on glutamate excitotoxicity. Glutamate is the predominant excitatory neurotransmitter in the mammalian brain and participates in mechanisms associated with long-term potentiation and synaptic plasticity [11]. Excessive production and release of glutamate, however, leads to neuronal injury and is a major pathogenic factor in many acute and chronic brain conditions, including Alzheimer's disease $[3,8-10,12]$.

In our search for novel compounds with neuroprotective effects against glutamate neurotoxicity, we focused in a class of compounds, the angiotensin receptor blockers (ARBs) or sartans, that effectively blocks the physiological AT1 receptor (AT1R) and therefore the effects of angiotensin II, the main active factor of the renin-angiotensin system [13] both in the periphery and the brain [14]. Excessive peripheral AT1R activity associates with hypertension, heart and kidney failure, peripheral vascular and tissue inflammation, and metabolic abnormalities such as insulin resistance [15-17]. Consequently, the use of sartans, because of their beneficial effects on inflammatory and metabolic alterations beyond their effect on blood pressure control, has become a cornerstone for the treatment of cardiovascular and chronic kidney disease [18]. In turn, increased brain AT1R stimulation associates with brain ischemia, bloodbrain barrier breakdown, $\mathrm{A} \beta$ production and toxicity, brain inflammation, traumatic brain injury and glutamate excitotoxicity, risk factors leading to neuronal injury, cognitive decline, and the incidence and progression of neurodegenerative diseases [19-26]. For this reason it is not surprising that sartans have been found to be effective neuroprotective compounds. In vitro experiments demonstrated that sartans ameliorate neuronal injury produced by glutamate excitotoxicity and high levels of interleukin (IL)-1 $\beta$, and microglia activation as a result of systemic administration of bacterial endotoxin (lipopolysaccharide (LPS)) [25, 27-29]. In rodent models of Alzheimer's disease, sartans (candesartan, losartan, valsartan and telmisartan) ameliorate all risk factors for human Alzheimer's disease, including protecting cerebral blood flow and cognition during stroke, decreasing inflammation and $A \beta$ neurotoxicity, and reducing traumatic brain injury [24, 26, 27, 30-37]. Furthermore, clinical studies indicate that ARBs protect cognition after stroke and during aging [15, 22, 38, 39], and cohort analyses reveal that treatment of hypertension with sartans significantly reduces the incidence and progression of Alzheimer's disease [40, 41].

To clarify the role of glutamate excitotoxicity, we used primary rat cerebellar granule cells (CGCs) in vitro. This is a well-characterized and reliable primary neuronal model to analyze mechanisms and excitotoxic neuronal damage and neuroprotection [42, 43]. Although in humans CGCs are not primary targets for Alzheimer's disease, rat CGCs are very sensitive to glutamate excitotoxicity, a major early injury factor in this illness, and are extensively used in Alzheimer's disease research [44-46]. We selected the ARB candesartan for our study because of its demonstrated neuroprotective effects on cultured primary cortical neurons, microglia and cerebrovascular endothelial cells, and its amelioration of brain inflammation in vivo [27] including reducing glutamateinduced apoptosis in cultured CGCs [25].

Our study was initially designed to provide mechanistic insight into the potential targets and pathways that may underlie glutamate-induced cell injury and its possible reversal by the neuroprotective action of candesartan. To this aim, we performed genome-wide expression analysis and evaluated the data with several pathway analysis programs: ingenuity pathway analysis (IPA), gene set enrichment analysis (GSEA) $[47,48]$ and Kyoto encyclopedia of genes and genomes (KEGG).

The strong correlation of our findings with many signal transduction mechanisms and pathways associated with Alzheimer's disease prompted us to determine whether there was an association between the changes in gene expression in our study with those found in postmortem brain samples from patients who suffered from Alzheimer's disease. To this end, we compared our results with alterations in gene expression published in two independent microarray studies of hippocampal samples obtained postmortem from brains of patients diagnosed with Alzheimer's disease. Because of evidence of cerebrovascular endothelial dysfunction in Alzheimer's disease, we wanted to establish which of the genes altered in Alzheimer's disease patients were predominantly expressed in cerebrovascular endothelial cells or in neurons. To clarify this point, we compared gene expressions altered in published Alzheimer's disease patients with published analysis of predominant gene 
expression in human cerebrovascular endothelial cells and neurons obtained by laser capture microdissection from postmortem dorsolateral prefrontal cortex samples and then we looked at the effect of candesartan on these gene signatures in our CGC study.

\section{Methods}

\section{Culture of primary neurons}

Animal housing, handling and experimentation were in compliance with guidelines and protocol approval by the NIMH (NIH) Institutional Animal Care and Use Committee (protocol MH002762-17), and followed guidelines of the US National Institute of Health Guide for the Care and Use of Laboratory Animals published by the US National Academy of Sciences (http://oacu.od.nih. gov/regs/index.htm).

We used primary cultures of rat primary CGCs, which are very sensitive to glutamate excitotoxicity and extensively used in Alzheimer's disease research [44-46]. CGCs were isolated from 8-day old Sprague Dawley rat pups (Charles Rivers Laboratories, Wilmington, MA, USA) as described previously [49, 50] which were euthanized by decapitation. Brains were dissected immediately and the cerebella were collected and placed in ice-cold Hank's balanced salt solution (Invitrogen, Carlsbad, CA, USA). After removal of the meninges, the cerebella were dispersed into the same buffer containing $0.025 \%$ trypsin (Invitrogen) and digested for $15 \mathrm{~min}$ at $37{ }^{\circ} \mathrm{C}$. Trypsin digestion was stopped by adding the same volume of Dulbecco's modified Eagle's medium (Invitrogen), supplemented with $10 \%$ fetal bovine serum (Invitrogen) and $0.1 \mathrm{mg} / \mathrm{ml}$ DNase I (Sigma-Aldrich, St. Louis, MO, USA). After gentle trituration, digested tissues were centrifuged at $1000 \mathrm{rpm}$ for $5 \mathrm{~min}$. The cell pellets were suspended in the complete Neurobasal culture medium supplemented with $2 \%$ B27 (Invitrogen) and $0.5 \mathrm{mM}$ GlutaMax (Invitrogen). After filtration through a $70 \mathrm{~mm}$ cell restrainer (BD Falcon, Vernon Hills, IL, USA), cells were plated at a density of $1 \times 10^{6}$ cells $/ \mathrm{ml}$ onto poly-L-lysine coated plates (Becton Dickinson and Company, Franklin Lakes, NJ, USA) or chamber glass slides (Nalge Nunc International, Naperville, IL, USA). Cultures were incubated in a humidified atmosphere of $5 \% \mathrm{CO}_{2} 95 \%$ air at $37{ }^{\circ} \mathrm{C}$. Cytosine arabinofuranoside (Invitrogen) $(10 \mu \mathrm{l})$ was added to the cultures $24 \mathrm{~h}$ after plating to arrest the growth of non-neuronal cells. Cultures of 6 to 7 days in vitro were used in this study. Immunocytochemical validation with antimicrotubuleassociated protein-2 antibody (EMD Millipore, Billerica, MA, USA) and 4-6-diamino-2-phenylindole (Invitrogen) revealed that more than $95 \%$ of the cells in our culture system were neurons at the time of experiment (data not shown).

\section{Cell culture treatments}

We performed microarray analysis of gene expression in four sets of rat primary neuronal cultures: controls; treated with candesartan at concentrations in the range of blood levels obtained in humans after oral administration [51]; exposed to excitotoxic glutamate concentrations [25]; and treated with candesartan before the exposure to glutamate. Excitotoxicity was induced by exposing cultures to $100 \mu \mathrm{M}$ glutamate (Sigma-Aldrich) and pretreated for $1 \mathrm{~h}$ with vehicle $(0.1 \%$ saline and $0.1 \mathrm{~N} \mathrm{Na}_{2} \mathrm{CO}_{3}$ at $\mathrm{pH}$ 7.4), or the AT1R blocker candesar$\tan (10 \mu \mathrm{M})$ (Sigma-Aldrich) dissolved in $0.1 \mathrm{~N} \mathrm{Na}_{2} \mathrm{CO}_{3}$, $\mathrm{pH}$ 7.4. After addition of candesartan, the compound was not removed and was present throughout the incubation. Candesartan and glutamate concentrations and timing of the experiments were selected on the basis of prior studies demonstrating protection of cultured neurons from inflammation and glutamate-induced injury $[25,27]$. Figure 1 is a flow chart for data analysis.

\section{Gene expression analysis}

Total RNA was extracted from CGC treated with vehicle, CGC treated with candesartan, CGC treated with glutamate and CGC treated with candesartan and glutamate. Each group consisted of five independent experiments. Standard procedures for labeling, hybridization, washing and staining were as per manufacturer's recommendation (Affymetrix, Santa Clara, CA, USA). Briefly, the RNA was purified using a RiboPure Kit (Ambion, Austin, TX, USA) according to the manufacturer's protocol. The quality and quantity of RNA were ensured using the Bioanalyzer (Agilent, Santa Clara, CA, USA) and NanoDrop (Thermo Scientific, Waltham, MA, USA), respectively. For RNA labeling, total RNA (300 ng) was used in conjunction with the Affymetrix-recommended protocol with the WT Plus Reagent Kit catalog \#902280. The hybridization cocktail containing the fragmented and labeled complementary DNAs (cDNAs) was hybridized to the Rat GeneChip 2.0 ST chips. The chips were washed and stained by the Affymetrix Fluidics Station using the standard format and protocols from Affymetrix. The probe arrays were stained with streptavidin phycoerythrin solution (Molecular Probes, Carlsbad, CA, USA) and enhanced by using an antibody solution containing $0.5 \mathrm{mg} / \mathrm{ml}$ biotinylated antistreptavidin (Vector Laboratories, Burlingame, CA, USA). The probe arrays were scanned using an Affymetrix Gene Chip Scanner 3000. Gene expression intensities were calculated using the Gene Chip Operating software 1.2 (Affymetrix). A GC-corrected robust multichip analysis (RMA) normalization model was used to correct for background, and nonspecific binding. All analyses were performed using Partek Genomics Suite (Fig. 1). The raw data is submitted to Gene Expression Omnibus (GEO) under accession GSE67036. 


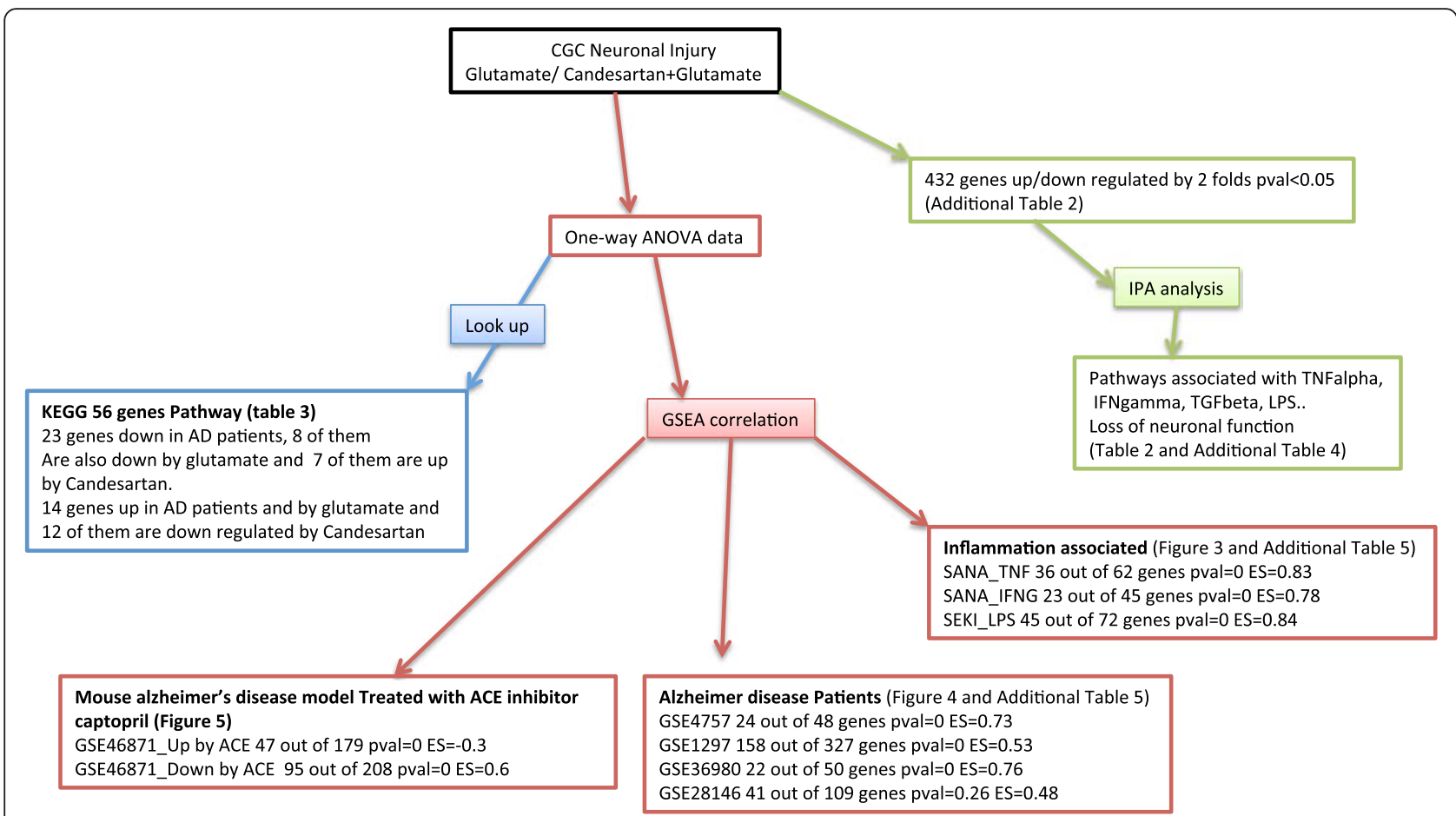

Fig. 1 Flow chart for data analysis. ACE angiotensin converting enzyme, AD Alzheimer's disease, ANOVA analysis of variance, CGC cerebellar granule cell, ES enrichment score, GSEA gene set enrichment analysis, IFN interferon, IPA ingenuity pathway analysis, KEGG Kyoto encyclopedia of genes and genomes, LPS lipopolysaccharide, pval p value, TGF transforming growth factor, TNF tumor necrosis factor

\section{Quantitative real-time polymerase chain reaction}

Aliquots from samples from the same experiment were used for quantitative real-time polymerase chain reaction (qPCR) and for microarray analysis. For qPCR we studied three individual independent samples, and each sample was analyzed in triplicate.

To determine gene expression, total RNA was isolated as indicated using $1 \mathrm{ml}$ TRIzol (Invitrogen), followed by purification using an RNeasy Mini kit (Qiagen, Valencia, CA, USA) according to the manufacturer's instructions. Synthesis of cDNA was performed using $0.6 \mathrm{mg}$ total RNA and Super-Script III first-Strand Synthesis kit (Invitrogen). qPCR was performed on DNA Engine Opticon (MJ Research, Waltham, MA, USA) with SYBR Green PCR Master Mix (Applied Biosystems, Foster City, CA, USA). qPCR was performed in a $20 \mu \mathrm{l}$ reaction mixture containing $10 \mu \mathrm{l}$ SYBR Green PCR Master Mix, $4 \mu \mathrm{l}$ cDNA and $0.3 \mu \mathrm{M}$ of each primer for a specific target. Primers for qPCR were synthesized by BioServe (Beltsville, MD, USA). The specific primers are listed in Additional file 1 (Table S1). The remaining reagents for RNA isolation and reverse transcription were from Invitrogen. The amplification conditions consisted of one denaturation/ activation cycle at $95^{\circ} \mathrm{C}$ for $10 \mathrm{~min}$, followed by 45 cycles at $95{ }^{\circ} \mathrm{C}$ for $15 \mathrm{~s}$ and $60{ }^{\circ} \mathrm{C}$ for $60 \mathrm{~s}$. Serial dilutions of cDNA from the same source as samples were used to obtain a standard curve. The individual targets for each sample were quantified by determining the cycle threshold and by comparison with the standard curve. The relative amount of the target mRNA was normalized with the housekeeping gene glyceraldehyde-3-phosphate dehydrogenase.

Multiple group comparisons for data obtained by qPCR were performed by one-way analysis of variance (ANOVA) followed by Newman-Keuls post-test. Statistical significance was determined using GraphPad Prism 5 Software (GraphPad Software, San Diego, CA, USA). In all cases, data are accepted as statistically significant given a probability value of $\leq 0.05$.

\section{Datasets description and microarray data mining}

To compare our data to published datasets, we used GSEA [52] (Fig. 1). The GSEA algorithm computes a ranked list of all genes from a microarray comparison between two conditions and identifies whether individual members of an a priori functionally defined gene set (black vertical bars) are enriched at either the top (red area) or bottom of the ranked genes (blue area) or randomly distributed across the whole ranked gene list, using a modified KolmogorovSmirnov statistic. These predefined gene sets are part of a functionally well-established and/or published pathway from databases such as KEGG [53], BioCarta [54], Reactome [55] and gene ontology. An enrichment score (green graph) is calculated based on the level to which a gene set 
is overrepresented at the top (positive correlation) or bottom (negative correlation) of the ranked gene list and is calculated as the maximum deviation from zero. Genes occurring at the very extreme (dark red or dark blue area) on either side of the ranked list are weighted more heavily compared with genes occurring in the middle (light red or light blue area) of the ranked gene list that contain genes that are not differentially expressed. Statistical significance is defined by the $p$-value, which is also adjusted for multiple hypothesis testing. A gene set-based permutation test of 1000 permutations was applied and genes were ranked according to Student's $t$ statistic. All other parameters were set to GSEA defaults [47, 48]. For a more comprehensive description of the GSEA [47, 48, 52] and the Broad Molecular Signatures Database v5.0 (MSigDB) [56] see $[47,48,52]$. The MSigDB actually consists of over 4000 different gene sets. Alternatively, we used microarray datasets from the GEO database [57] to derive gene sets that we then used for GSEA analysis. IPA [58] (Ingenuity Systems, Redwood City, CA, USA) was used to identify canonical pathways associated with the differentially expressed genes. All of the differentially expressed genes were included in the analysis.

Datasets from normal/Alzheimer's disease whole hippocampus tissue comparisons (GSE1297 [59] GSE48350 [60], and GSE36980 [61]) and from laser capture microdissected normal neuronal/endothelial cell comparisons (GSE12679 [62] and GSE12293 [63]) were downloaded from NCBI's GEO database [57] and imported into Partek Genomics Suite software (Partek, Inc., St. Louis, MI, USA) (Fig. 1). After RMA normalization, differential gene expression was accessed by one-way ANOVA. For microarray cross-platform comparisons we used a $p$ value of $<0.05$ and a 1.2-fold change cutoff. Raw data from these datasets were analyzed with Partek Genomics Suites under similar conditions used for the CGC data. In order to avoid cross-platform heterogeneity we focused only on datasets generated on the Affymetrix chips.

GSE1297 [59] (Fig. 1) is a dataset collected from nine postmortem normal and 22 Alzheimer's disease patients with different degrees of severity, obtained from the Brain Bank of the Alzheimer's disease Center of the University of Kentucky. Only seven severe cases (mean Braak stage 5.9, mean age 84 years old) were included in this analysis.

GSE48350 [60] (Fig. 1) is a dataset collected from postmortem human hippocampus tissue from 33 controls and 26 Alzheimer's patients (Braak stage 5-6, mean age 79-90 years old) and obtained from the NIH/NIA Alzheimer's Disease Research Center Brain Bank (Bethesda, MD, USA) and profiled on the Affymetrix Human Genome U133 Plus 2.0 Array.

GSE36980 [61] (Fig. 1) is a dataset from hippocampus gene expression of ten controls and seven Alzheimer patients (83 to 105 years old at Braak stages 5 to 6) selected from autopsy samples obtained from Hisajama, Japan residents and profiled on the Affymetrix Human Gene 1.0 ST Arrays.

GSE12679 [62] (Fig. 1) is a dataset from a laser capture microdissection of microvascular endothelial cells and neurons from human dorsolateral prefrontal cortex obtained at autopsy from 12 control individuals, obtained from the Stanley Medical Research Institute brain collection (Bethesda, MD, USA) and profiled on the Affymetrix Human Genome U133 Plus 2.0 Array.

GSE12293 [63] (Fig. 1) is a dataset from autopsy samples of human dorsolateral prefrontal cortex obtained from the Stanley Medical Research Institute brain collection (Bethesda, MD, USA). Neurons from six control subjects and endothelial cells from seven control subjects were isolated by laser-capture microdissection and profiled on the Affymetrix Human Genome U133 Plus 2.0 Array.

Detailed demographic information may be consulted in the selected references [59-63].

GSE46871 [64] (Fig. 1) is a dataset from hippocampal gene expression of $\mathrm{Tg} 2576$ mice, a rodent model of Alzheimer's disease, comparing untreated controls and mice treated with the angiotensin converting enzyme inhibitor (ACEI) captopril.

\section{Results}

Global gene expression analysis Candesartan prevents glutamate-induced upregulation or downregulation of multiple genes in primary neurons

Differential gene expression comparing results from glutamate-treated neurons with those of vehicle-treated neurons yielded over 1100 transcripts significantly upor downregulated by glutamate (Additional file 2: Table S2). Differential gene expression shows over 800 transcripts (including microRNAs and noncoding RNAs) that are up- or downregulated when candesartan was added prior to glutamate, as compared with those exposed to glutamate only (Additional file 2: Table S2).

Candesartan completely prevented the glutamateinduced up- or downregulation of 501 of these transcripts (twofold or higher, $p<0.05$; Additional file 2: Table S2). Interestingly, the comparison of neurons treated with candesartan to the control untreated neurons generated only a few genes with no functional annotation that may represent the system noise, confirming the fact that candesartan does not have any significant effect on normal neurons (Additional file 2: Table S2).

\section{Confirmation of microarray results by qPCR Candesartan prevents glutamate-induced gene upregulation}

We confirmed microarray results by determination of expression of a number of genes upregulated by glutamate 
exposure by qPCR. In all these genes, candesartan pretreatment very significantly, and in many cases completely, prevented glutamate-induced upregulation. The exception was superoxide dismutase 2 ; in this case there was a clear trend, but the results were not statistically significant (Fig. 2; Additional file 3: Figure S1, Additional file 4: Figure S2 and Additional file 5: Figure S3).

\section{Pathway analysis}

\section{Specific diseases and functions, and upstream regulators} associated with glutamate exposure and candesartan

\section{treatment}

The list of functionally annotated genes from the glutamate versus glutamate + candesartan (423 unique genes) was submitted to IPA analysis [58]. As a result, cell movement, cell death and lesion formation, inflammation and synthesis of reactive oxygen species, diabetes and glucose metabolism, vascular disease and blood vessel development came top of the list of diseases and functions (Table 1; Additional file 6: Table S3). Many genes within these pathways were up- or downregulated by glutamate, and these changes were significantly prevented by candesartan (Additional file 2: Table S2).

Within the IPA program, analysis of upstream regulators of these differentially expressed genes included the well-known inflammatory associated cytokines tumor necrosis factor (TNF) alpha, IL-1 $\beta$ and interferon (IFN) gamma, LPS, the growth factor transforming growth factor (TGF) beta-1, and five upstream regulator drugs PD98059, SB203580, U0126, SP600125 and LY294002 (Table 2; Additional file 7: Table S4). Additional upstream regulators were amyloid precursor protein (APP), retinoid acid (Tretinoin) and apolipoprotein E (APOE) (Table 2; Additional file 7: Table S4).

\section{Gene set enrichment analysis}

Association with Alzheimer's disease

To further define candesartan molecular and functional pathways, we ran our glutamate versus glutamate + candesartan CGC microarray data through GSEA [52]. As predicted, inflammatory pathways associated with IFN- $\gamma$, TNF $\alpha$, IL-1 $\beta$ and LPS, and several mechanisms of apoptosis

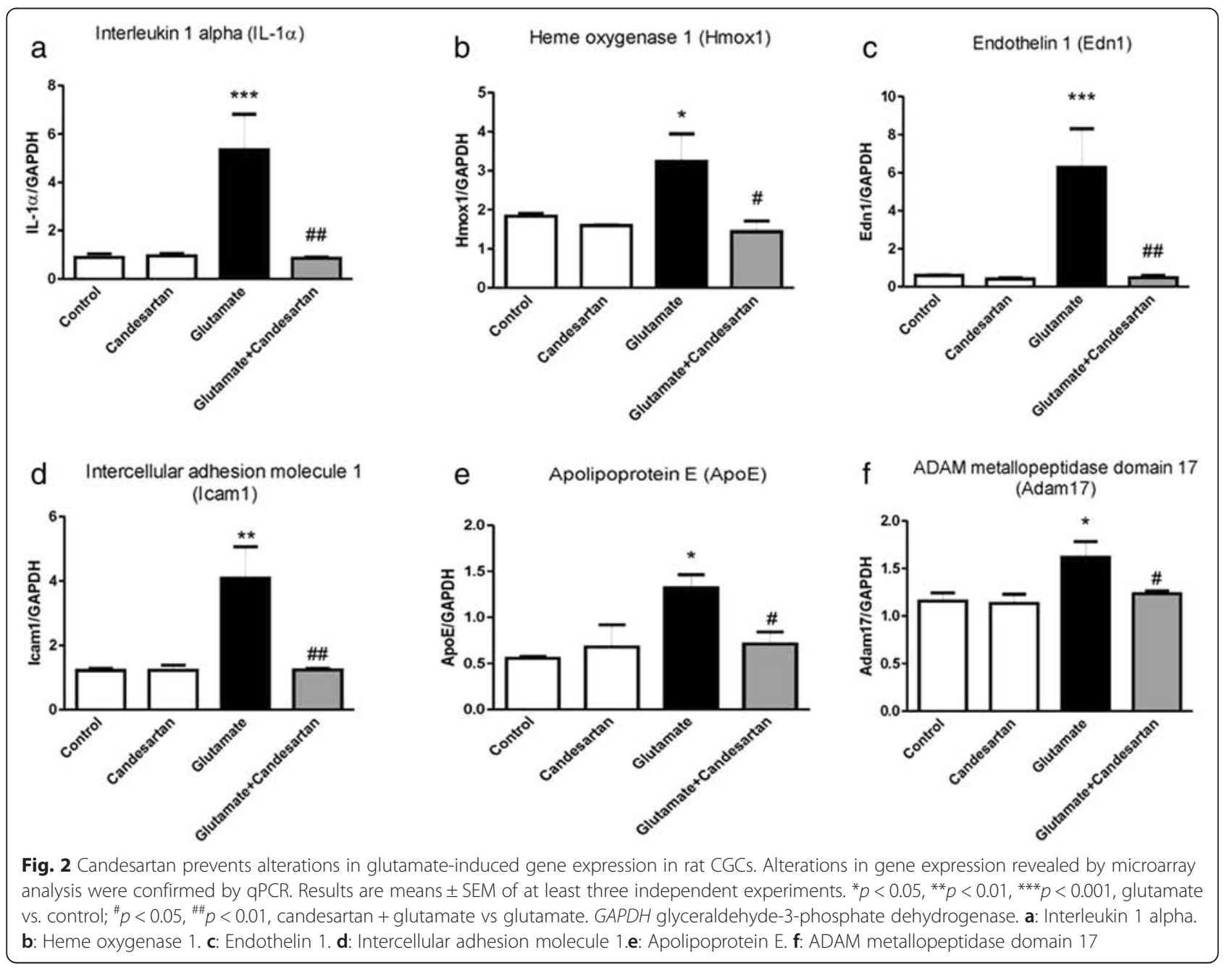


Table 1 Representative IPA categories associated with glutamate andcandesartan-glutamate comparison

\begin{tabular}{|c|c|c|c|}
\hline Categories & Diseases or functions annotation & $p$ value & No. of molecules \\
\hline Cellular movement & Cell movement & $8.33 \mathrm{E}-52$ & 170 \\
\hline Cell-to-cell signaling and interaction, cellular movement & Recruitment of cells & $1.61 \mathrm{E}-49$ & 72 \\
\hline Hematological system development and function, tissue morphology & Quantity of blood cells & $4.80 \mathrm{E}-46$ & 114 \\
\hline Inflammatory response & Inflammation of organ & $1.61 \mathrm{E}-45$ & 119 \\
\hline Organismal injury and abnormalities & Lesion formation & $1.67 \mathrm{E}-44$ & 73 \\
\hline Cardiovascular disease & Vascular disease & $1.33 \mathrm{E}-42$ & 105 \\
\hline Immunological disease & Systemic autoimmune syndrome & $7.31 \mathrm{E}-41$ & 108 \\
\hline Endocrine system disorders, gastrointestinal disease, metabolic disease & Diabetes mellitus & $1.60 \mathrm{E}-36$ & 102 \\
\hline Cell death and survival & Cell death & $2.16 \mathrm{E}-35$ & 191 \\
\hline Metabolic disease & Glucose metabolism disorder & $1.13 \mathrm{E}-33$ & 109 \\
\hline Inflammatory disease & Chronic inflammatory disorder & $1.54 \mathrm{E}-33$ & 94 \\
\hline Cardiovascular system development and function, organismal development & Development of blood vessel & $1.07 \mathrm{E}-27$ & 83 \\
\hline Free radical scavenging & Synthesis of reactive oxygen species & $5.38 \mathrm{E}-27$ & 59 \\
\hline
\end{tabular}

The number of molecules represents the number of genes differentially expressed between glutamate and candesartan + glutamate that are part of the pathway category. The whole ingenuity pathway analysis (IPA) output is provided as Additional file 3: Table S3

were the most statistically relevant pathways (Fig. 3; Additional file 8: Table S5 and Additional file 9: Table S9). Genes upregulated by excitotoxic concentrations of glutamate are associated with genes upregulated by the IFN- $\gamma$, IL6 , IL-1 $\beta$, TNF $\alpha$ and LPS-induced inflammation, involving chemokine signaling, focal adhesion, actin cytoskeleton, apoptosis by nutrient deprivation and extracellular matrix receptor interaction pathways. The glutamate-induced upregulation of these genes was normalized by candesartan treatment. Conversely, candesartan prevented the glutamate-induced downregulation of genes associated with neuronal function (cholinergic, dopamine and gammaaminobutyric acid A receptors) (Additional file 8: Table S5).

At the disease level, the GSEA shows a striking association with Alzheimer's and Parkinson's disease (Additional file 8: Table S5 and Additional file 9: Table S9). Genes that are upregulated in a published dataset (GSE36980 [61]; Fig. 1) of hippocampus samples obtained from Alzheimer's disease patients strongly correlate with genes upregulated in neurons exposed to glutamate ( $p$ value $=0.0, \mathrm{FDR}=0.09$, enrichment score $=0.75$ ) (Fig. 4; Additional file 8: Table S5 and Additional file 9: Table S9). Conversely, genes that are downregulated in this published dataset strongly correlate with genes downregulated in neurons exposed to glutamate (Figs. 1 and 4; Additional file 8: Table S5 and Additional file 9: Table S9).

Correlation of changes in gene expression in rat CGCs with those reported in a mouse model of Alzheimer's disease Association of candesartan treatment in CGCs and captopril treatment in APPswe mice

Gene expression affected by glutamate and glutamate-candesartan in our model shows perfect correlation with the alterations in gene expression observed in the APPswe mouse model of Alzheimer's disease treated with the ACEI captopril (GSEA 46871) [64]. Genes that were upregulated by glutamate in our study (effects prevented by candesar$\tan )$ have been reported to be downregulated by captopril $(p$ value $=0.0, \mathrm{FDR}=0.0$, enrichment score $=0.60)$ and, inversely, genes downregulated by glutamate (this effect being prevented by candesartan in our model) were upregulated by captopril treatment in the APPswe mice ( $p$ value $=0.0$, $\mathrm{FDR}=0.0$, enrichment score $=-0.30)($ Figs. 1 and 5$)$.

\section{KEGG analysis \\ Association of differentially expressed genes in rat CGCs and Alzheimer's disease hippocampus}

We used the KEGG [53] Alzheimer's disease pathways gene set to compare to genes differentially expressed in postmortem hippocampus from Alzheimer's disease patients (GSEA 48350) [60] (Fig. 1) and their counterpart in our rat CGC study (Fig. 1). As seen in Table 3, within the KEGG Alzheimer's disease 56 genes network, 23 of them are down regulated in hippocampus from Alzheimer's disease patients (changes observed in GSE48350) and eight of them are also downregulated by glutamate in our rat neuronal study. Changes in seven of these eight genes are prevented by treatment with candesartan in our rat neuronal study. Moreover, of the 14 genes upregulated in hippocampus from Alzheimer's patients, 12 were upregulated also by glutamate in our study, and in turn all these changes were prevented by candesartan treatment (Fig. 1 and Table 3).

\section{Analysis of gene expression in specific cell populations Differential alterations in gene expression preferentially expressed in neurons and cerebrovascular cells}

We sought to define the predominant cellular origin of genes with altered expression in postmortem hippocampus 
Table 2 Representative top 30 upstream regulators of genes differentially expressed between glutamate and glutamate + candesartan

\begin{tabular}{|c|c|c|}
\hline Upstream regulator & Molecule type & $p$ value of overlap \\
\hline Tumor necrosis factor & Cytokine & $1.06 \mathrm{E}-74$ \\
\hline Lipopolysaccharide & Chemical drug & $3.26 \mathrm{E}-63$ \\
\hline Interleukin-1 beta & Cytokine & $1.02 \mathrm{E}-61$ \\
\hline Interferon gamma & Cytokine & 4.75E-61 \\
\hline Transforming growth factor beta-1 & Growth factor & $1.99 \mathrm{E}-49$ \\
\hline Nuclear factor kappa B (complex) & Complex & $1.80 \mathrm{E}-43$ \\
\hline Dexamethasone & Chemical drug & $2.74 \mathrm{E}-42$ \\
\hline Interleukin-6 & Cytokine & $2.16 \mathrm{E}-40$ \\
\hline Colony Stimulating Factor 2 (CSF2) & Cytokine & 1.57E-39 \\
\hline Interleukin-10 & Cytokine & $6.06 \mathrm{E}-39$ \\
\hline Of Kappa Light Polypeptide Gene Cin B Cells (IKBKB) & Kinase & 7.92E-39 \\
\hline Interleukin-13 & Cytokine & $1.46 \mathrm{E}-38$ \\
\hline Poly rl:rC-RNA & Chemical reagent & 4.53E-38 \\
\hline Signal transducer and activator of transcription 3 (STAT3) & Transcription regulator & $1.80 \mathrm{E}-37$ \\
\hline Amyloid precursor protein & Other & $2.86 \mathrm{E}-37$ \\
\hline $\begin{array}{l}\text { Nuclear Factor Of Kappa Light Polypeptide Gene } \\
\text { Enhancer in B Cell Inhibitor, Alpha (NFKBIA) }\end{array}$ & Transcription regulator & 4.57E-36 \\
\hline Myeloid differentiation primary response gene 88 (MYD88) & Other & 4.97E-36 \\
\hline Tretinoin & Chemical_endogenous mammalian & $6.44 \mathrm{E}-36$ \\
\hline E. coli B4 lipopolysaccharide & Chemical toxicant & 1.36E-35 \\
\hline PD98059 & Chemical_-kinase inhibitor & $1.85 E-35$ \\
\hline Beta-estradiol & Chemical_endogenous mammalian & 9.64E-35 \\
\hline Interleukin-4 & Cytokine & $1.46 \mathrm{E}-34$ \\
\hline Apolipoprotein E & Transporter & $2.32 \mathrm{E}-33$ \\
\hline Platelet-derived growth factor BB & Complex & 2.99E-33 \\
\hline Conserved Helix -Loop Helix Ubiquitous Kinase (CHUK) & Kinase & $6.05 E-33$ \\
\hline Toll-like receptor 4 & Transmembrane receptor & $2.55 \mathrm{E}-32$ \\
\hline Angiotensinogen (AGT) & Growth factor & $3.51 \mathrm{E}-32$ \\
\hline Phorbol myristate acetate & Chemical drug & $6.73 E-32$ \\
\hline SB203580 & Chemical_-kinase inhibitor & 1.17E-31 \\
\hline Tumor necrosis factor superfamily member 11 (TNFSF11) & Cytokine & $1.79 \mathrm{E}-31$ \\
\hline
\end{tabular}

A full and detailed list is provided as Additional file 7: Table S4

from Alzheimer disease patients and their preferential expression in neurons or endothelial cells and the possible differential regulation of these genes by glutamate and glutamate-candesartan in our neuronal study. To this end we compared gene expression of two datasets generated from hippocampus of Alzheimer's disease patients and normal controls (GSE48350 [60] and GSE36980 [61]) with two datasets generated from neurons and cerebrovascular endothelial cells from normal human dorsolateral prefrontal cortex, specifically isolated by laser capture microdissection (GSE12293 and GSE12679) [62, 63]. We then compared the genes predominantly expressed in neurons and cerebrovascular cells in the Alzheimer's samples with genes regulated in our neuronal cultures by glutamate and by glutamate-candesartan.

Using a 1.2-fold change cutoff and a $p$ value below 0.05 , we found 580 genes commonly up regulated in both Alzheimer patient datasets (Fig. 6). Of these 580 upregulated genes, 166 and 124 were predominantly expressed in cerebrovascular endothelial cells compared to 19 and 6 for neurons within GSE12293 [63] and GSE12679 [62] datasets, respectively. On the other hand, there are 1430 genes commonly downregulated in Alzheimer's disease tissues. Of these, 381 and 329 were 


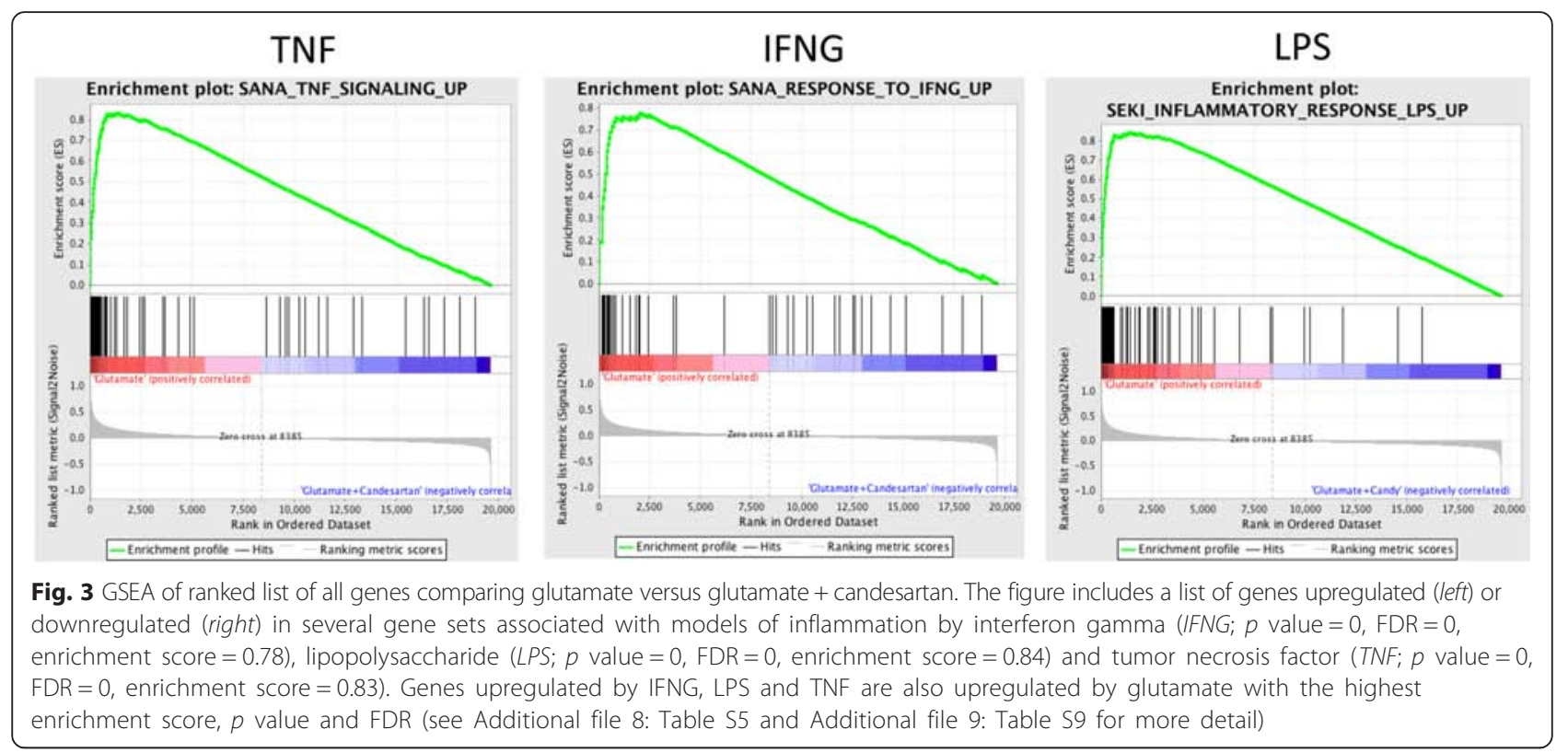

more expressed in neurons and only 38 and 27 were expressed in cerebrovascular endothelial cells within GSE12293 and GSE12679 datasets, respectively (Fig. 6).

We found striking correlations when we considered the preferential cellular expression, as revealed by the laser capture detection studies, with the gene expression in hippocampus from Alzheimer's disease patients and with the results of our neuronal study. Most of the genes upregulated in Alzheimer's disease hippocampus and by glutamate in our neuronal study that were normalized when candesartan was added to glutamate were of endothelial origin (70 versus 4 and 48 versus 2 in GSE12293

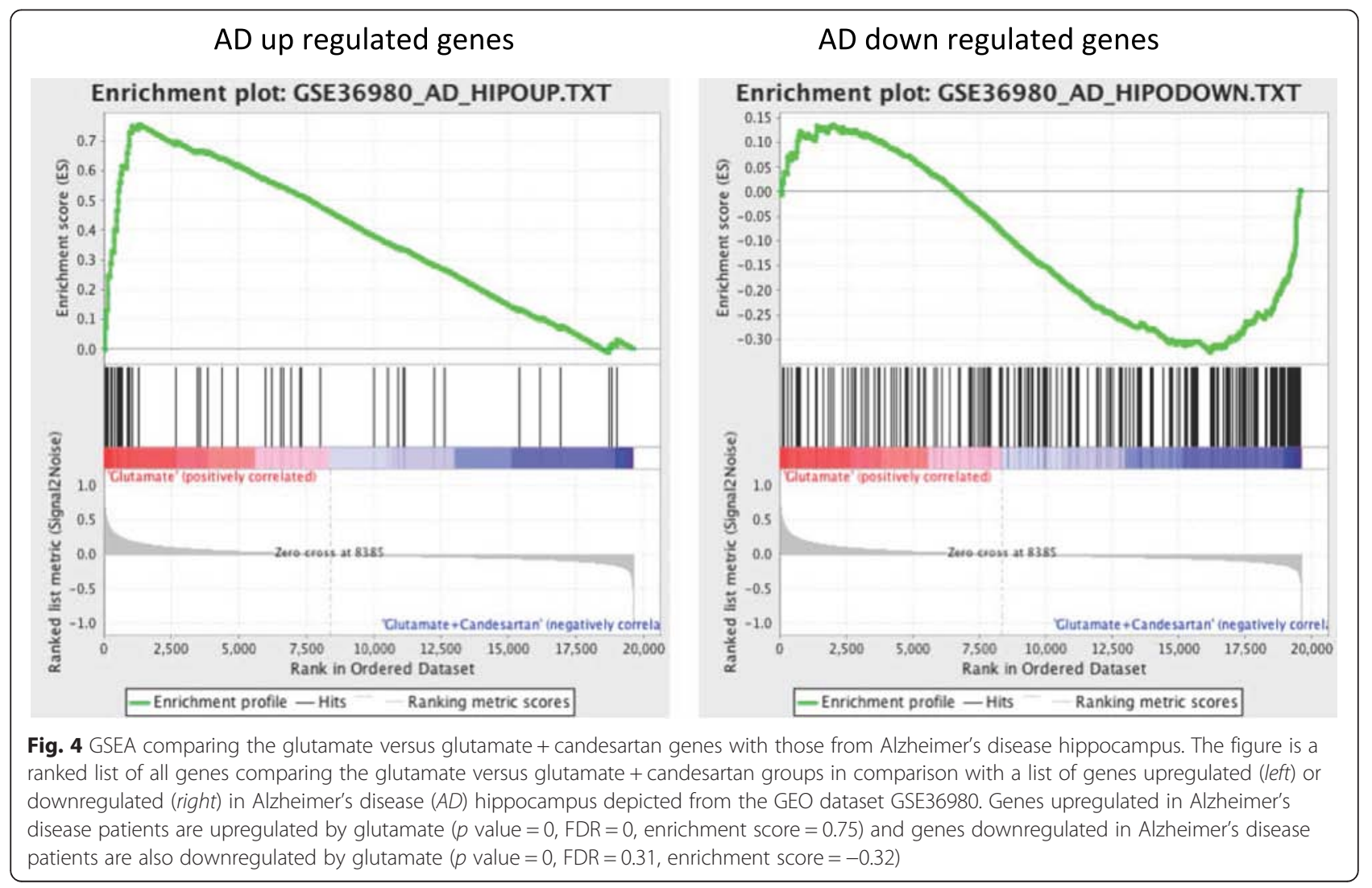




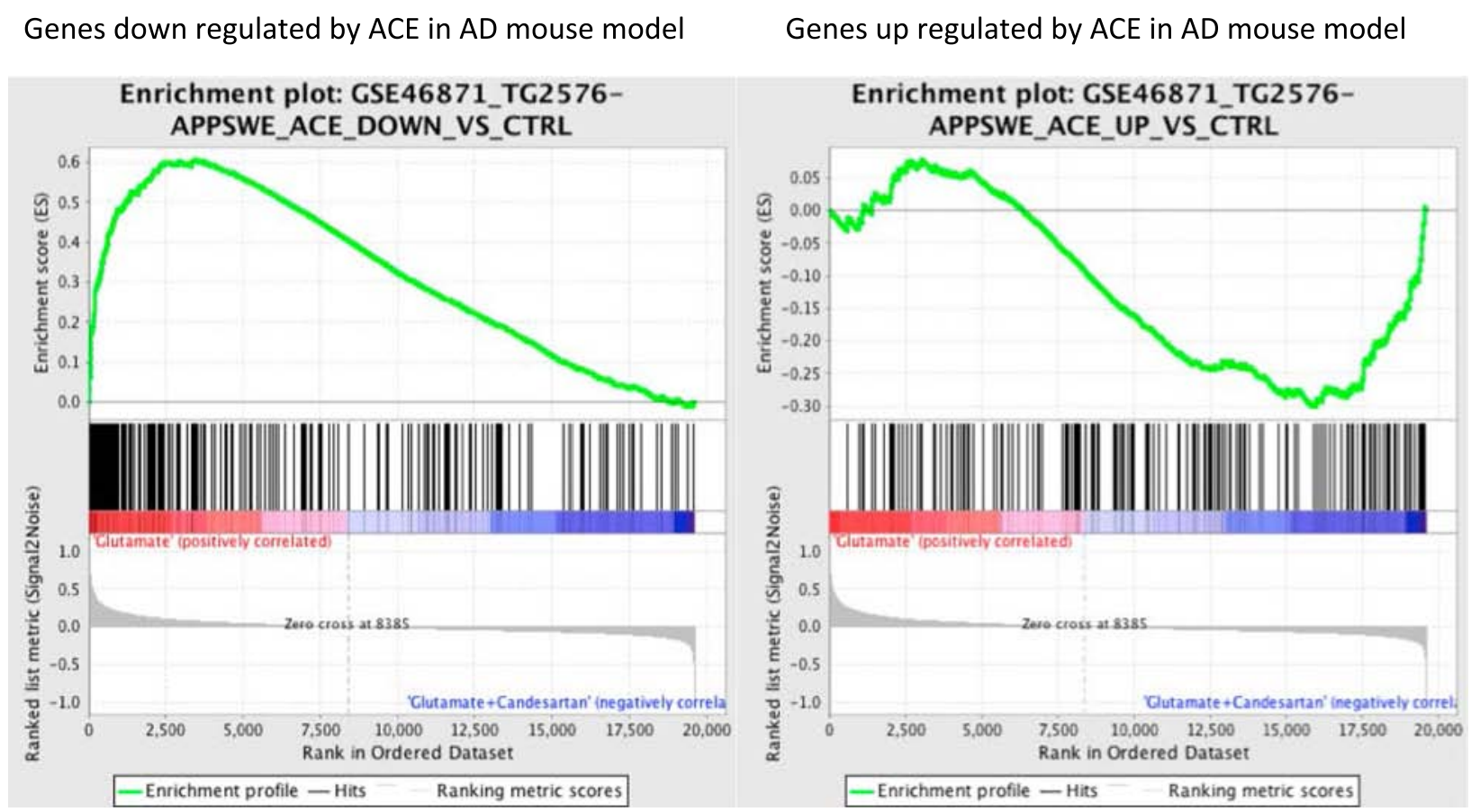

Fig. 5 GSEA comparing the glutamate versus glutamate + candesartan genes with those from the APPswe mouse. The figure is a ranked list of all genes comparing the glutamate versus glutamate + candesartan groups in comparison with a list of genes upregulated (left) or downregulated (right) in the hippocampus of the APPswe mouse model of Alzheimer's disease depicted from the GEO dataset GSE46871. Genes upregulated by glutamate in our neuronal culture are downregulated by treatment with an angiotensin converting enzyme (ACE) inhibitor in the APPswe mouse model ( $p$ value $=0, F D R=0.0$, enrichment score $=-0.60$ ). Inversely, genes downregulated by glutamate in our neuronal culture are upregulated by treatment with an ACE inhibitor in the APPswe mouse model ( $p$ value $=0, F D R=0$, enrichment score $=-0.30$ )

[63] and GSE12679 [62], respectively). Conversely, most of the genes downregulated in hippocampus from Alzheimer's disease patients and by glutamate in our rat CGC study, changes normalized when candesartan was added to glutamate, were of neuronal origin (122 versus 18 and 74 versus 4 in GSE12293 [63] and GSE12679 [62], respectively) (Fig. 6).

For the genes upregulated in Alzheimer's disease and by glutamate in our study, downregulated by candesartan, and, predominately expressed in endothelial cells, the pathway analysis revealed cellular movement/migration, extracellular matrix proteins, apoptosis, angiogenesis and vasculogenesis, and their most significant upstream regulators are beta-estradiol and TGF $\beta 1$ (Additional file 10: Figure S4, Additional file 11: Table S6 and Additional file 12: Table S7). On the other hand, genes upregulated in Alzheimer's disease and downregulated by candesartan that are predominately expressed in neurons did not show any pathway significance, most probably due to the low number of genes.

Conversely, genes downregulated in Alzheimer's disease and by glutamate in our neuronal study, which are upregulated by candesartan in our cultures, were predominately expressed in neurons. Pathway analysis revealed neurological diseases, neurodegeneration, neuronal apoptosis and disorders of basal ganglia (Additional file 13: Figure S5), and the most significant upstream regulator was the nuclear factor, erythroid 2-like 2 (NFE2L2, Nrf2) gene (Additional file 14: Table S8).

\section{Discussion}

The overall goal of the study was to determine whether glutamate-induced alterations in gene expression in our primary neuronal culture were normalized by candesartan, and whether these changes correlated with alterations in gene expression in postmortem hippocampus of Alzheimer's disease patients. We hypothesized that, if present, significant correlations would provide major preclinical evidence of beneficial therapeutic effects of candesartan.

There were several major findings in our study. Based on our results, we propose that candesartan may be neuroprotective on neuronal glutamate-induced injury. There were multiple functionally annotated genes strongly associated with Alzheimer's disease and impressively correlated with alterations in gene expression in autopsy samples from Alzheimer's disease hippocampus. We found novel functions differentially associated with 
Table 3 Look-up of Alzheimer's disease associated genes from KEGG pathways and their expression in hippocampus from Alzheimer's patients (GSE48350 dataset) and rat CGC glutamate + candesartan treatment

\begin{tabular}{|c|c|c|c|c|c|c|c|}
\hline $\begin{array}{l}\text { KEGG gene } \\
\text { symbol }\end{array}$ & $\begin{array}{l}\text { Gene } \\
\text { symbol }\end{array}$ & $\begin{array}{l}\text { GSE48350 } \\
\text { hippocampus ctrl } \\
\text { vs AD } p \text { value }\end{array}$ & $\begin{array}{l}\text { GSE48350 } \\
\text { hippocampus ctrl } \\
\text { vs AD fold change }\end{array}$ & $\begin{array}{l}\text { CGC } \\
\text { glutamate vs } \\
\text { ctrl } p \text { value }\end{array}$ & $\begin{array}{l}\text { CGC glutamate } \\
\text { vs ctrl fold } \\
\text { change }\end{array}$ & $\begin{array}{l}\text { CGC glutamate vs } \\
\text { glutamate }+ \\
\text { candesartan } p \text { value }\end{array}$ & $\begin{array}{l}\text { CGC glutamate vs } \\
\text { glutamate + candesartan } \\
\text { fold change }\end{array}$ \\
\hline NMDAR & GRIN1 & 0.000 & -2.184 & 0.037 & -1.191 & 0.733 & 1.026 \\
\hline $\mathrm{Cn}$ & РРP3СВ & 0.000 & -2.111 & 0.002 & -1.245 & 0.001 & 1.277 \\
\hline CDK5 & cdk5 & 0.000 & -2.039 & 0.357 & -1.041 & 0.436 & 1.035 \\
\hline p35 & Cdk5r1 & 0.000 & -2.031 & 0.774 & 1.040 & 0.391 & -1.126 \\
\hline $\mathrm{Cn}$ & ppp3ca & 0.000 & -1.749 & 0.000 & -1.221 & 0.003 & 1.158 \\
\hline SERCA & ATP2A2 & 0.000 & -1.691 & 0.002 & -1.176 & 0.001 & 1.183 \\
\hline PLC & PLCB1 & 0.000 & -1.653 & 0.038 & -1.060 & 0.000 & 1.147 \\
\hline ERK2 & MAPK1 & 0.000 & -1.578 & 0.012 & -1.074 & 0.026 & 1.063 \\
\hline CXIII & uqcrfs1 & 0.000 & -1.535 & 0.254 & 1.099 & 0.002 & 1.379 \\
\hline NOS & NOS1 & 0.000 & -1.529 & 0.403 & -1.060 & 0.38 & 1.063 \\
\hline SNCA & Snca & 0.000 & -1.472 & 0.755 & 1.044 & 0.242 & 1.179 \\
\hline GSK3B & GSK3B & 0.000 & -1.464 & 0.000 & -1.236 & 0.000 & 1.167 \\
\hline$C \times V$ & Atp5a1 & 0.000 & -1.407 & 0.011 & 1.143 & 0.023 & 1.123 \\
\hline TAU & mapt & 0.000 & -1.358 & 0.544 & -1.051 & 0.899 & 1.01 \\
\hline$C x \mid$ & Ndufv1 & 0.000 & -1.348 & 0.090 & 1.128 & 0.002 & 1.285 \\
\hline VDCC & CACNA1C & 0.007 & -1.25 & 0.781 & 1.015 & 0.004 & -1.209 \\
\hline CytC & COX411 & 0.000 & -1.244 & 0.002 & 1.194 & 0.000 & -1.237 \\
\hline $\mathrm{Gq}$ & GNAQ & 0.001 & -1.221 & 0.140 & -1.054 & 0.029 & -1.085 \\
\hline Fe65 & APBB1 & 0.002 & -1.195 & 0.376 & 1.127 & 0.765 & -1.04 \\
\hline BID & BID & 0.04 & -1.192 & 0.008 & 1.116 & 0.561 & -1.021 \\
\hline Cxll & $\mathrm{SDHA}$ & 0.002 & -1.18 & 0.392 & 1.071 & 0.005 & 1.301 \\
\hline APP-BP1 & Nae1 & 0.024 & -1.145 & 0.021 & -1.267 & 0.006 & 1.344 \\
\hline BAD & $\mathrm{Bad}$ & 0.05 & -1.143 & 0.396 & -1.068 & 0.151 & 1.121 \\
\hline BACE & BACE1 & 0.224 & -1.113 & 0.005 & -1.302 & 0.003 & 1.326 \\
\hline PERK & eif2ak3 & 0.166 & -1.108 & 0.001 & -1.198 & 0.041 & 1.096 \\
\hline IRE1A & ERN1 & 0.229 & -1.068 & 0.019 & 1.093 & 0.000 & -1.284 \\
\hline CASP9 & Casp9 & 0.245 & -1.058 & 0.495 & 1.081 & 0.228 & -1.15 \\
\hline PEN2 & psenen & 0.413 & -1.052 & 0.006 & -1.135 & 0.086 & 1.073 \\
\hline NEP & MME & 0.497 & -1.038 & 0.036 & 1.371 & 0.012 & -1.485 \\
\hline IDE & $\mathrm{IDE}$ & 0.898 & 1.006 & 0.074 & -1.112 & 0.004 & 1.211 \\
\hline FADD & Fadd & 0.716 & 1.015 & 0.067 & 1.146 & 0.001 & -1.351 \\
\hline NCSTN & NCSTN & 0.266 & 1.042 & 0.704 & 1.031 & 0.318 & 1.085 \\
\hline $\mathrm{APH}-1$ & aph1a & 0.239 & 1.058 & 0.360 & 1.052 & 0.36 & 1.052 \\
\hline $\mathrm{APH}-1$ & $\mathrm{APH} 1 \mathrm{~B}$ & 0.204 & 1.063 & 0.032 & -1.121 & 0.336 & -1.048 \\
\hline CASP12 & CASP12 & 0.067 & 1.072 & 0.000 & 1.988 & 0.000 & -1.742 \\
\hline$A B A D$ & HSD17B10 & 0.181 & 1.081 & 0.000 & 1.351 & 0.049 & -1.07 \\
\hline PLC & plcb3 & 0.018 & 1.085 & 0.000 & 1.652 & 0.000 & -1.455 \\
\hline CASP3 & Casp3 & 0.032 & 1.091 & 0.010 & -1.234 & 0.02 & 1.204 \\
\hline LRP & Irp1 & 0.107 & 1.1 & 0.017 & 1.293 & 0.02 & -1.283 \\
\hline APAF1 & Apaf1 & 0.018 & 1.108 & 0.641 & -1.034 & 0.458 & 1.055 \\
\hline PSEN & Psen 1 & 0.011 & 1.117 & 0.096 & -1.079 & 0.935 & 1.004 \\
\hline ATF6 & ATF6B & 0.07 & 1.14 & 0.001 & 1.248 & 0.01 & -1.174 \\
\hline
\end{tabular}


Table 3 Look-up of Alzheimer's disease associated genes from KEGG pathways and their expression in hippocampus from Alzheimer's patients (GSE48350 dataset) and rat CGC glutamate + candesartan treatment (Continued)

\begin{tabular}{|c|c|c|c|c|c|c|c|}
\hline CALPAIN & CAPN1 & 0.003 & 1.154 & 0.000 & 1.490 & 0.000 & -1.298 \\
\hline ADAM17 & Adam17 & 0.000 & 1.165 & 0.000 & 2.442 & 0.000 & -2.505 \\
\hline APOE & APOE & 0.033 & 1.18 & 0.000 & 2.023 & 0.005 & -1.325 \\
\hline RYR & RYR3 & 0.001 & 1.184 & 0.000 & 1.480 & 0.000 & -1.707 \\
\hline CASP8 & CASP8 & 0.008 & 1.242 & 0.002 & 1.180 & 0.01 & -1.14 \\
\hline IP3R & ITPR1 & 0.024 & 1.271 & 0.002 & 1.245 & 0.031 & -1.146 \\
\hline CASP7 & casp7 & 0.001 & 1.28 & 0.000 & 1.139 & 0.000 & -1.149 \\
\hline CaM & CALM2 & 0.001 & 1.305 & 0.004 & 1.219 & 0.006 & -1.202 \\
\hline $\mathrm{CaM}$ & calml4 & 0.000 & 1.446 & 0.000 & 1.425 & 0.015 & -1.226 \\
\hline LPL & Lpl & 0.02 & 1.481 & 0.000 & 4.445 & 0.000 & -2.672 \\
\hline FasTNFR1 & TNFRSF1A & 0.001 & 1.551 & 0.000 & 1.953 & 0.000 & -1.615 \\
\hline APP & App & NA & NA & 0.838 & 1.008 & 0.118 & -1.07 \\
\hline GAPD & Gapdh & NA & NA & 0.338 & 1.040 & 0.843 & 1.008 \\
\hline ERK1 & Mapk3 & NA & NA & 0.040 & 1.084 & 0.006 & -1.124 \\
\hline
\end{tabular}

AD Alzheimer's disease, CGC cerebellar granule cell, ctrl control, KEGG Kyoto encyclopedia of genes and genomes, NA not available

genes predominantly expressed in neurons and in cerebrovascular endothelial cells.

Candesartan profoundly influenced glutamate-induced neuronal injury, since candesartan prevented glutamateinduced alterations in gene expression in about 800 of the over 1100 transcripts upregulated or downregulated by glutamate (Additional file 2: Table S2). Candesartan effects were unrelated to the proposed stimulation of angiotensin II (AT2) receptors by AT1R blockade, since AT2 receptors are not expressed in CGCs [25].

Using qPCR, we confirmed glutamate-induced upregulation, normalized by candesartan, of a number of these genes, including several factors with fundamental roles in APP metabolism and Alzheimer's disease, such as ADAM metallopeptidase domain 17 [65-67] and APOE [68-72] (Fig. 2; Additional file 3: Figure S1, Additional file 4: Figure S2 and Additional file 5: Figure S3).

Inflammation plays a significant role in the pathogenesis of Alzheimer's disease [6, 7, 73, 74]. Glutamate excitotoxicity upregulated many pro-inflammatory genes associated with Alzheimer's disease [25, 75-89] and were normalized by candesartan (Fig. 2; Additional file 3: Figure S1, Additional file 4: Figure S4 and Additional file 5: Figure S3). Glutamate also upregulated the expression of some genes involved in antiinflammatory processes, and candesartan prevented these changes (Fig. 2; Additional file 3: Figure S1, Additional file 4: Figure S2 and Additional file 5: Figure S3) [31, 90-93]. We hypothesize that while glutamate increases inflammation, at the same time it sets in motion a powerful anti-inflammatory response that is not necessary when the inflammatory response is prevented by candesartan.
Under the conditions of our experiments, we found that, when added after glutamate injury, candesartan does not protect neurons from cell injury [25]. We interpreted that candesartan administration, although it may not reverse glutamate-induced cell injury which has already occurred, will prevent further glutamate-induced injury. Since glutamate excitotoxicity is a long-term process during progression of Alzheimer's disease [3, 8$10,12]$, we believe our results are translationally relevant. The IPA analysis of the list of functionally annotated genes with their expression altered by glutamate and normalized when compared with the glutamate + candesartan group (over 400 genes) supported the proposed key role of inflammation in the pathogenesis of Alzheimer's disease, [6, 7], agreed with the demonstrated major anti-inflammatory effect of candesartan [22, 27], and revealed many additional and novel diseases and functions, such as cell death and lesion formation, diabetes and glucose metabolism and vascular disease main risk factors for Alzheimer's disease $[4,5]$ (Table 1; Additional file 6: Table S3).

Furthermore, IPA analysis of upstream regulators of these genes included APP, APOE and retinoic acid (Tretionin), which play major roles in Alzheimer's disease [65-72] (Table 2; Additional file 7: Table S4) and revealed five kinase inhibitors, PD98059, SB203580, U0126, SP600125 and LY294002 (Table 2), that are part of the mitogen-activated protein kinase kinase/c-Jun $\mathrm{N}$ terminal kinase/extracellular regulated kinase/p38-mitogen activated kinase/TGF $\beta-1$ (MEK/JNK/ERK1/2/p38/ TGF $\beta$ ) pathways, reduce inflammation and toxicity, and have been associated with Alzheimer's disease [85, 94-98]. We found that the influence of PD98059 and SB203580 


\section{Hippocampus 1.2 folds up or down and p-value $<0.05$}

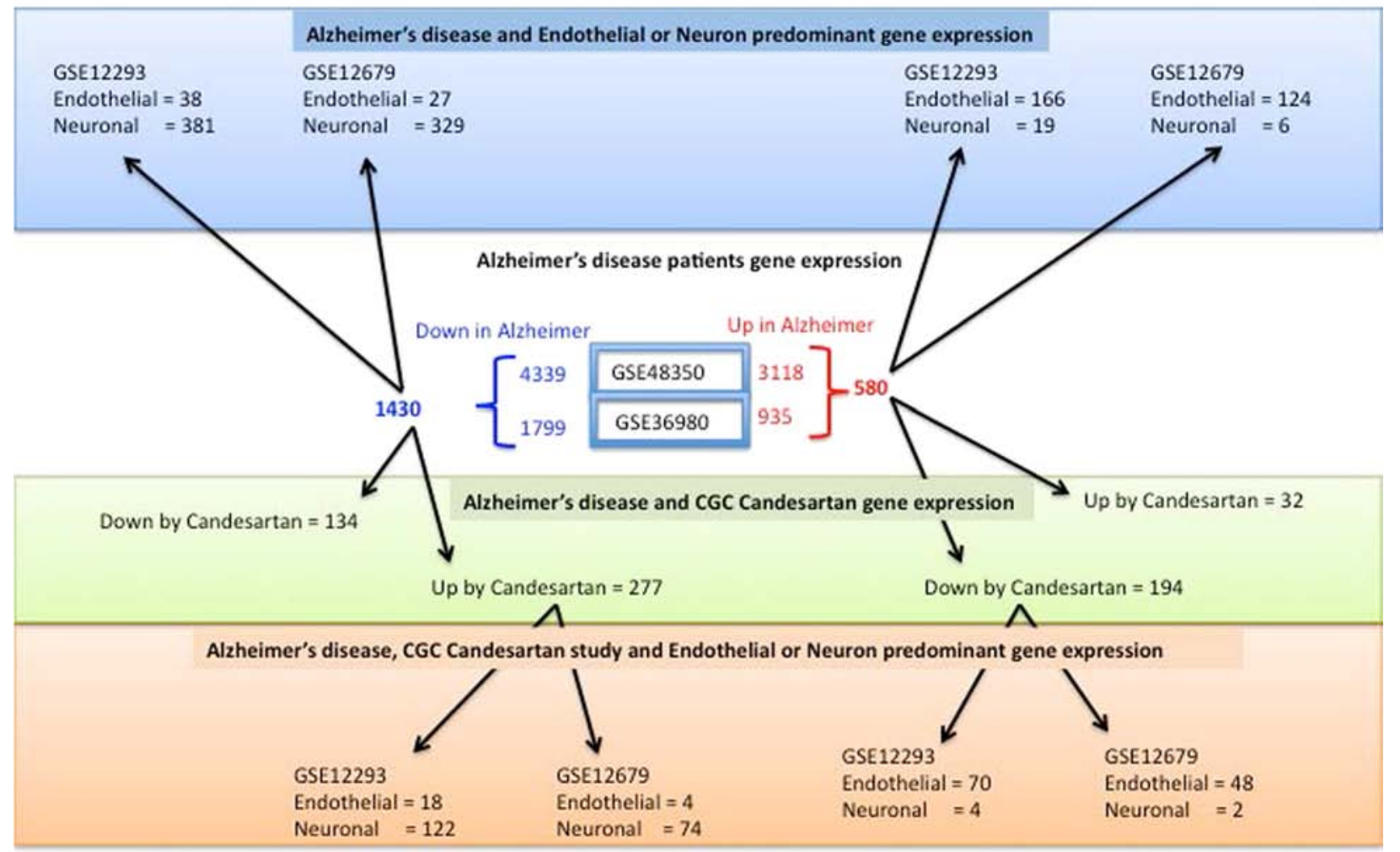

Fig. 6 Cellular origin of gene expression in Alzheimer's disease hippocampus. There are 580 genes upregulated (red) and 1430 downregulated (b/ue) differentially expressed transcripts in hippocampus from Alzheimer's disease patients which are common to both GSE48350 and GSE1297 datasets. On the top side (blue block), the expression of these genes is then looked up in two datasets (GSE12293 and 12679) of normal laser capture microdissected neurons and cerebrovascular endothelial cells. On the bottom side (green block), the expression of these genes is compared to those differentially expressed in rat cerebellar granule cells (CGCS) treated with glutamate alone versus glutamate + candesartan and then looked-up in the two datasets (GSE12293 and 12679) of normal laser capture microdissected neurons and cerebrovascular endothelial cells (orange block). Note that the majority of the commonly expressed genes downregulated in Alzheimer's disease hippocampus and upregulated by candesartan have a predominant expression in neurons. Conversely, the majority of the commonly expressed genes upregulated in Alzheimer's disease hippocampus and downregulated by candesartan have a predominant endothelial expression

over inflammatory genes was similar to that revealed by candesartan in our study [94, 95]. In support of the present findings, we have earlier reported that AT1R blockade prevents glutamate-induced ERK1/2, JNK and cJun activation $[25,29]$, demonstrating that the effect of candesartan is upstream of ERK1/2-p38MAPK.

GSEA supported the findings revealed by IPA. Inflammatory, chemokine signaling, focal adhesion, actin cytoskeleton, apoptosis and extracellular matrix receptor interaction pathways were most relevant, and the expression of the associated genes, upregulated by glutamate, was normalized by candesartan (Fig. 3; Additional file 8: Table S5). Conversely, candesartan prevented the glutamate-induced downregulation of genes associated with neuronal function (Additional file 8: Table S5).

Many genes (19 out of 53) in the KEGG Alzheimer's disease reference pathway were altered in postmortem Alzheimer's disease patients and by glutamate and normalized by candesartan. The pathways included mitochondrial dysfunction, APP processing, including $\beta$-secretase (BACE1), apoptosis, DNA damage, lipid peroxidase, $\mathrm{Ca}^{2+}$ signaling pathway and $\mathrm{Ca}^{2+}$ overload (Table 3).

Most remarkably, GSEA showed a striking association between changes observed in our neuronal culture and those observed in published datasets of hippocampal samples obtained from Alzheimer's disease patients. Genes up- or downregulated in Alzheimer's disease hippocampus [59-61] strongly correlated with genes upor downregulated in neurons exposed to glutamate and prevented by candesartan (Fig. 4 and Table 3; Additional file 8: Table S5 and Additional file 9: Table S9).

Our results indicate that although the primary neurons studied here, CGCs, are not the primary targets for Alzheimer's disease [44-46], upon glutamate injury they exhibited multiple mechanisms closely associated with 
those revealed in human hippocampal autopsy samples. Some of the glutamate-induced injury mechanisms observed in CGCs have been replicated in primary cortical neuronal cultures [25]. While analysis of postmortem samples has limitations because of the premortem agonal process and postmortem changes in glutamate metabolism, there was a striking correlation in alterations in gene expression between the two independent published datasets evaluated in our study. Furthermore, the normal controls used for the Alzheimer's disease postmortem samples were also postmortem samples normalized for age and gender. Moreover, there were impressive correlations between our neuronal culture findings and those revealed in a mouse model of Alzheimer's disease (Fig. 5), supporting the validity of our comparative analysis.

The predominant cellular expression of the genes altered in Alzheimer's disease hippocampus and in our neuronal culture revealed two different pathological processes (Fig. 6). Multiple genes, upregulated in Alzheimer's disease hippocampus and by glutamate in our neuronal culture, and normalized by candesartan, were predominantly expressed in human cerebrovascular endothelial cells when compared to neurons. IPA analysis of these genes revealed cellular movement/migration, extracellular matrix proteins, apoptosis, angiogenesis and vasculogenesis as principal functions controlled by these genes, and their most significant upstream regulators were TGF $\beta 1$ and betaestradiol. TGF $\beta 1$ has been strongly associated with microvascular alterations in Alzheimer's disease [99]. There is substantial evidence for a role of beta-estradiol, and in particular hippocampus-synthesized 17 $\beta$-estradiol in synaptic plasticity and cognition $[100,101]$ and for neuroprotective effects of nonfeminizing estrogens [102]. The glutamate-induced upregulation of genes selectively overexpressed in cerebrovascular endothelial genes strongly supports the proposed role of alterations in the microvasculature in Alzheimer's disease, not only as a risk factor but also playing a major role in its pathogenesis [4, 103-108].

Conversely, pathway analysis of genes predominantly expressed in human neurons when compared to human cerebrovascular endothelial cells and downregulated in Alzheimer's disease hippocampus and by glutamate in our neuronal cultures, normalized by candesartan (Fig. 6), revealed neurological diseases, neurodegeneration, neuronal apoptosis and disorders of basal ganglia as principal related diseases. For these genes, the most significant upstream regulator was the NFE2L2 or Nrf2 gene that has been associated with the early stages of Alzheimer's disease [109]. These results are concordant with the well-known loss of neural function in Alzheimer's disease.
It is tempting to speculate that pathological processes in Alzheimer's disease may be based on two sequential and/or concomitant processes: enhanced inflammation in microvascular endothelial cells and neuronal injury. Although candesartan is a drug that was designed to work on the hypertensive endothelial vascular system, our data indicates that candesartan may directly protect neurons from injury, a proposal supported by a previous observation [27].

Our report adds novel findings to the substantial body of evidence strongly suggesting that blockade of AT1R is a new avenue for the treatment of Alzheimer's disease $[22,110]$. Preclinical experiments indicate that excessive brain angiotensin II activity through overactivation of brain AT1R leads to cognitive loss associated with hippocampal long-term potentiation blockade, inhibition of the cholinergic system and stimulation of $\mathrm{A} \beta$ production and tau phosphorylation [22, 26, 111]. Of note, AT1R gene expression is upregulated by glutamate, and this change is normalized by candesartan (Additional file 2 : Table S2).

Conversely, in preclinical models, AT1R blockade ameliorates hypertension, traumatic brain injury, brain ischemia and diabetes, the main modifying risk factors for Alzheimer's disease, effects that include reduction of cognitive loss [22]. In addition, AT1R blockade ameliorates cognitive loss in most of the rodent models of Alzheimer's disease by reducing brain inflammation, excessive oxidative stress and in some cases decreasing $A \beta$ production, oligomerization, tau phosphorylation and reducing blood flow [22, 26, 31, 110-114].

Supporting the role of enhanced AT1R activity in Alzheimer's disease, there was a correlation between alterations in gene expression in the APPswe mouse model of Alzheimer's disease treated with captopril, an ACEI reducing angiotensin II formation, and those found in our study [64] (Fig. 5). ARBs reduce inflammation in human circulating monocytes exposed to LPS [28, 115], and prevent glutamate-induced neuronal apoptosis [25]. Clinical studies demonstrate that AT1R blockers reduce major risk factors for Alzheimer's disease, [22, 110, 116]; observational and cohort studies reported that AT1R blockade delayed development of Alzheimer's disease and protect cognition [22, 117]. There are increasing calls to conduct randomized controlled trials to effectively test the hypothesis that AT1R blockade may be a novel therapeutic approach for the treatment of Alzheimer's disease [22, 117-119], and in particular including patients at the very early stages of the disease [120].

The mechanism of candesartan neuroprotection from glutamate excitotoxicity has been associated with blockade of the glutamate NMDA receptor [25]. In addition, candesartan neuroprotection may involve an increase in glutamate uptake into the cell [121]. Furthermore, AT1R 
blockade may not be the only mechanism responsible for the neuroprotective effect of candesartan. Some ARBs, in particular telmisartan and candesartan, are powerful activators of a major neuroprotective mechanism, the peroxisome proliferator-activated receptor gamma (PPAR $\gamma$ ) [22, 25, 28, 33], and PPAR $\gamma$ activation plays a significant role in neuroprotection from glutamate excitotoxicity in cultured CGCs [25].

Our gene analysis revealed major associations of the gene alterations reported here with Parkinson's disease, neurological diseases and neurodegeneration. These observations support the hypothesis that ARB neuroprotection may not only be effective in Alzheimer's disease, but also in other neurodegenerative diseases $[22,23,110]$.

\section{Conclusions}

Our data may be interpreted as evidence of direct neuroprotective effects of candesartan in neurons, and of common disease processes that may underlie the in vitro acute gene alterations reported here and long-term mechanisms of cell injury in the late stages of Alzheimer's disease. We provide novel evidence for candesartan neuroprotection through early molecular mechanisms of injury in this illness, such as glutamate-induced neuronal injury. Candesartan not only prevents inflammation but also novel pathogenic mechanisms such as risk factors for the disease and alterations in APP processing and mitochondrial function. The differential glutamate-induced alterations in genes preferentially expressed in cerebrovascular endothelial cells or neurons indicate the possibility of two different and interrelated pathogenic mechanisms, revealing multiple targets for candesar$\tan$ neuroprotection. Our report supports the proposal to use ARBs as drugs of choice for the treatment of early cognitive loss.

\section{Additional files}

Additional file 1: Table S1. List of primer sequences used for $\mathrm{QPCR}$. (PDF $86 \mathrm{~kb}$ )

Additional file 2: Table S2. Differentially expressed genes in glutamate and glutamate + candesartan groups. Differentially expressed genes between glutamate versus glutamate + candesartan (spreadsheet \#2) and between glutamate versus control (spreadsheet \#3) and between candesartan versus control (spreadsheet \#4). The common genes (spreadsheet \#1) represent genes that are differentially expressed in both comparisons. There is a complete reversal of the effect of glutamate by candesartan on all the 501 genes in common. (XLSX 267 kb)

Additional file 3: Figure S1. Candesartan prevents glutamate-induced alterations in gene expression in rat CGCs. Alterations in gene expression revealed by microarray analysis were confirmed by qPCR. Results are means \pm SEM of at least three independent experiments. ${ }^{*} p<0.05,{ }^{* *} p<$

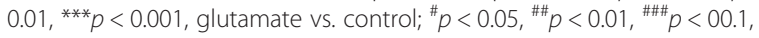
Candesartan + glutamate vs glutamate. (PDF $74 \mathrm{~kb}$ )

Additional file 4: Figure S2. Candesartan prevents glutamate-induced inflammation in rat CGCs. Alterations in gene expression revealed by microarray analysis were confirmed by $\mathrm{QPCR}$. Results are means \pm SEM of at least three independent experiments. ${ }^{*} p<0.05,{ }^{*} p<0.01$, glutamate vs. control; ${ }^{\#} p<0.05,{ }^{\# \#} p<0.01$, candesartan + glutamate vs glutamate. (PDF $98 \mathrm{~kb}$ )

Additional file 5: Figure S3. Candesartan prevents glutamate-induced inflammation in rat CGCs. Alterations in gene expression revealed by microarray analysis were confirmed by $\mathrm{qPCR}$. Results are means $\pm \mathrm{SEM}$ of at least three independent experiments. ${ }^{*} p<0.05,{ }^{* *} p<0.01$ glutamate vs. control; ${ }^{*} p<0.05,{ }^{\# \#} p<0.01$, candesartan + glutamate vs glutamate. (PDF $62 \mathrm{~kb}$ )

Additional file 6: Table S3. IPA disease and/or function list for genes altered in glutamate versus glutamate + candesartan groups. (XLSX 67 kb)

Additional file 7: Table S4. List of upstream regulation analysis for genes differentially expressed between glutamate and glutamate + candesartan. (XLSX 200 kb)

Additional file 8: Table S5. GSEA for the genes altered in glutamate versus glutamate + candesartan. Table S5 is a GSEA for the genes with altered expression in our glutamate versus glutamate + candesartan groups, and their correlation with several gene sets/signatures associated with specific molecular functions, diseases, INFG, IL6, TNF, LPS and neuronal functions. (PDF $5309 \mathrm{~kb}$ )

Additional file 9: Table S9. Complete GSEA analysis output of CGCs treated with glutamate and glutamate + candesartan and several inflammatory gene signatures and gene signature from postmortem Alzheimer's disease patient and a mouse model of Alzheimer's disease. (XLSX $4051 \mathrm{~kb})$

Additional file 10: Figure S4. Pathways associated with genes preferentially expressed in cerebrovascular endothelial cells. Figure S4 notes pathways associated with genes that are upregulated in Alzheimer's disease and downregulated by candesartan in our neuronal cultures and are more expressed in endothelial cells. Genes are red in the outer circle and pathways are in orange in the inside circle. Orange dotted lines are for positive effect and blue dotted lines are for negative effect of the gene on the pathway. (PDF $940 \mathrm{~kb}$ )

Additional file 11: Table S6. IPA of upstream regulators of genes preferentially expressed in cerebrovascular endothelial cells. Table S6 notes the upstream regulators of genes that are upregulated in Alzheimer's disease and downregulated by candesartan in our neuronal cultures, and are of preferentially expressed in endothelial cells. (XLS $118 \mathrm{~kb}$ )

Additional file 12: Table S7. IPA of diseases and functions annotation of genes preferentially expressed in cerebrovascular endothelial cells. Table S7 notes the diseases and functions that are upregulated in Alzheimer's disease and downregulated by candesartan and are preferentially expressed in cerebrovascular endothelial cells. (XLS 126 kb)

Additional file 13: Figure S5. Pathways associated with genes preferentially expressed in neurons. Figure S5 notes pathways that are downregulated in Alzheimer's disease and upregulated by candesartan in our neuronal cultures. Genes are in green in the outer circle and pathways are in orange (activated) or blue (inhibited) in the inside circle. Orange dotted lines are for positive effect and blue dotted lines are for negative effect of the gene on the pathway. (PDF 892 kb)

Additional file 14: Table S8. IPA of upstream regulators of genes preferentially expressed in neurons. Table $\mathbf{S} 8$ notes the upstream regulators of genes that are downregulated in Alzheimer's disease and upregulated by candesartan in our neuronal cultures, and are preferentially expressed in human neurons. (XLS $40 \mathrm{~kb}$ )

\section{Abbreviations}

$A \beta$ : Amyloid beta; ACEl: Angiotensin converting enzyme inhibitor; ANOVA: Analysis of variance; APOE: Apolipoprotein E; APP: Amyloid precursor protein; ARB: Angiotensin receptor blocker; AT1R: Angiotensin 1 receptor; AT2: Angiotensin 2 receptor; CDNA: Complementary DNA; CGC: Cerebellar granule cell; ERK: Extracellular regulated kinase; GEO: Gene Expression Omnibus; GSEA: Gene set enrichment analysis; IFN: Interferon; IL: Interleukin; IPA: Ingenuity pathway analysis; JNK: c-Jun N-terminal kinase; KEGG: Kyoto encyclopedia of genes and genomes; LPS: Lipopolysaccharide; MEK: Mitogen-activated protein kinase kinase; MSigDB: Broad Molecular 
Signatures Database v5.0; PPAR : peroxisome proliferator-activated receptor gamma; qPCR: Quantitative real-time polymerase chain reaction; RMA: Robust multichip analysis; TGF: Transforming growth factor; TNF: Tumor necrosis factor.

\section{Competing interests}

The authors declare that they have no competing interests.

\section{Authors' contributions}

AGE participated in the design of the study, performed all gene and statistical analysis, analyzed data and wrote the draft and final manuscript. $\mathrm{RH}$ performed all cell culture and gPCR assays and helped to draft the final manuscript. JMS participated in the design of the study, supervised cell culture and gPCR assays, and wrote the draft and final manuscript. All authors read and approved the final manuscript.

\section{Acknowledgments}

We would like to thank Weiwei Wu for her technical assistance with microarray processing.

AGE was supported by the National Human Genome Research Institute, National Institutes of Health, Bethesda, MD 20892. RH and JMS were supported by the Division of Intramural Research Programs, National Institute of Mental Health, National Institutes of Health, Department of Health and Human Services, USA (MH 002762-16).

\section{Author details}

'Comparative genomics and Cancer Genetics Branch, National Human Genome Research Institute, National Institutes of Health, Bethesda, MD 20892, USA. ${ }^{2}$ Section on Pharmacology, National Institute of Mental Health, National Institutes of Health, Bethesda, MD 20892, USA. ${ }^{3}$ Department of Pharmacology and Physiology, Georgetown University Medical Center, SE402 Med/Dent, 3900 Reservoir Road, Washington, DC 20057, USA.

\section{Received: 26 September 2015 Accepted: 8 December 2015}

\section{HWW}

\section{References}

1. Alzheimer's Association. 2013 Alzheimer's disease facts and figures. Alzheimers Dement. 2013;9:208-45.

2. Mullane K, Williams M. Alzheimer's therapeutics: continued clinical failures question the validity of the amyloid hypothesis - but what lies beyond? Biochem Pharm. 2013;85:289-305.

3. Pérez-Palma E, Bustos Bl, Villamán CF, Alarcón MA, Avila ME, Ugarte GD, et al., Alzheimer's Disease Neuroimaging Initiative; NIA- LOAD/NCRAD Family Study Group. Collaborators (448), Overrepresentation of glutamate signaling in Alzheimer's disease: network-based pathway enrichment using meta-analysis of genome-wide association studies. PLoS One. 2014:9:e95413. doi:10.1371/journal.pone.0095413. eCollection 2014.

4. Kelleher RJ, Soiza RL. Evidence of endothelial dysfunction in the development of Alzheimer's disease: is Alzheimer's a vascular disorder? Am J Cardiovasc Dis. 2013;3:197-226.

5. Rincon F, Wright CB. Current pathophysiological concepts in cerebral smal vessel disease. Front Aging Neurosci. 2014;6:24

6. Takeda S, Sato N, Morishita R. Systemic inflammation, blood-brain barrier vulnerability and cognitive/non-cognitive symptoms in Alzheimer disease: relevance to pathogenesis and therapy. Front Aging Neurosci. 2014;6:171.

7. Latta $\mathrm{CH}$, Brothers HM, Wilcock DM. Neuroinflammation in Alzheimer's disease; a source of heterogeneity and target for personalized therapy. Neuroscience 2014 (14)00820-3. doi:10.1016/j.neuroscience.2014.09.061.

8. Esposito Z, Belli L, Toniolo S, Sancesario G, Bianconi C, Martorana A. Amyloid $\beta$, glutamate, excitotoxicity in Alzheimer's disease: are we on the right track? CNS Neurosci Ther. 2013;19:549-55.

9. Talantova M, Sanz-Blasco S, Zhang X, Xia P, Akhtar MW, Okamoto S, et al. $A \beta$ induces astrocytic glutamate release, extrasynaptic NMDA receptor activation, and synaptic loss. Proc Natl Acad Sci U S A. 2013;110:E2518-27.

10. Danysz W, Parsons CG. Alzheimer's disease, $\beta$-amyloid, glutamate, NMDA receptors and memantine—searching for the connections. Br J Pharmacol. 2012;167:324-52

11. Coyle JT, Puttfarcken P. Oxidative stress, glutamate, and neurodegenerative disorders. Science. 1993;262:689-95.
12. Lau A, Tymianski M. Glutamate receptors, neurotoxicity and neurodegeneration. Pflugers Arch. 2010:460:525-42.

13. Timmermans PB, Wong PC, Chiu AT, Herblin WF, Benfield P, Carini DJ, et al. Angiotensin || receptors and angiotensin I| receptor antagonists. Pharmacol Rev. 1993:45:205-51.

14. Saavedra JM. Brain and pituitary angiotensin. Endocr Rev. 1992;13:329-80.

15. Chrysant SG, Chrysant GS, Chrysant C, Shiraz M. The treatment of cardiovascular disease continuum: focus on prevention and RAS blockade. Curr Clin Pharmacol. 2010;5:89-95.

16. Konstam MA, Neaton JD, Dickstein K, Drexler H, Komajda M, Martinez FA, et al. Effects of high-dose versus low-dose losartan on clinical outcomes in patients with heart failure (HEAAL study): a randomized, double-blind trial. ancet. 2009:374:1840-8.

17. Savoia C, Schiffrin EL. Vascular inflammation in hypertension and diabetes: molecular mechanisms and therapeutic interventions. Clin Sci. 2007;112:375-84.

18. Michel MC, Foster C, Brunner HR, Liu L. A systematic comparison of the properties of clinically used angiotensin II type 1 receptor antagonists. Pharmacol Rev. 2013;65:809-48.

19. Fleegal-DeMotta MA, Doghu S, Banks WA. Angiotensin II modulates BBB permeability via activation of the AT(1) receptor in brain endothelial cells. J Cereb Blood Flow Metab. 2009;29:640-7.

20. Nishimura Y, Ito T, Saavedra JM. Angiotensin II AT(1) blockade normalizes cerebrovascular autoregulation and reduces cerebral ischemia in spontaneously hypertensive rats. Stroke. 2000;31:2478-86.

21. Phillips Ml, de Oliveira EM. Brain renin angiotensin in disease. J Mol Med. 2008:86:715-22.

22. Saavedra JM, Angiotensin II. AT(1) receptor blockers as treatments for inflammatory brain disorders. Clin Sci (Lond). 2012;123:567-90.

23. Saavedra JM, Sánchez-Lemus E, Benicky J. Blockade of brain angiotensin II AT1 receptors ameliorates stress, anxiety, brain inflammation and ischemia: therapeutic implications. Psychoneuroendocrinology. 2011;36:1-18.

24. Tsukuda K, Mogi M, Iwanami J, Min LJ, Sakata A, Jing F, et al. Cognitive deficit in amyloid-beta-injected mice was improved by pretreatment with a low dose of telmisartan partly because of peroxisome proliferator-activated receptor-gamma activation. Hypertension. 2009:54:782-7.

25. Wang J, Pang T, Hafko R, Benicky J, Sanchez-Lemus E, Saavedra JM. Telmisartan ameliorates glutamate-induced neurotoxicity: roles of AT(1) receptor blockade and PPAR activation. Neuropharmacology. 2014;79:249-61.

26. Zhu D, Shi J, Zhang Y, Wang B, Liu W, Chen Z, et al. Central angiotensin II stimulation promotes $\beta$ amyloid production in Sprague Dawley rats. PLoS One. 2011;6:e16037. doi:10.1371/journal.pone.0016037.

27. Benicky J, Sánchez-Lemus E, Honda M, Pang T, Orecna M, Wang J, et al. Angiotensin II AT1 receptor blockade ameliorates brain inflammation. Neuropsychopharmacology. 2011;36:857-70.

28. Pang T, Benicky J, Wang J, Orecna M, Sanchez-Lemus E, Saavedra JM. Telmisartan ameliorates lipopolysaccharide-induced innate immune response through peroxisome proliferator-activated receptor- activation in human monocytes. J Hypertens. 2012;30:87-96.

29. Pang T, Wang J, Benicky J, Sánchez-Lemus E, Saavedra JM. Telmisartan directly ameliorates the neuronal inflammatory response to IL-1B partly through the JNK/C-Jun and NADPH oxidase pathways. J Neuroinflammation. 2012;9:102.

30. Ando H, Zhou J, Macova M, Imboden H, Saavedra JM. Angiotensin II AT1 receptor blockade reverses pathological remodeling and inflammation in brain microvessels of spontaneously hypertensive rats. Stroke. 2004:35:1726-31.

31. Danielyan L, Klein R, Hanson L, Buadze M, Schwab M, Gleiter CH, et al. Protective effects of intranasal losartan in the APP/PS1 transgenic mouse model of Alzheimer disease. Rejuvenation Res. 2010;13:195-201.

32. Ito T, Yamakawa H, Bregonzio C, Terrón JA, Falcón-Neri A, Saavedra JM. Protection against ischemia and improvement of cerebral blood flow in genetically hypertensive rats by chronic pretreatment with an angiotensin II AT1 antagonist. Stroke. 2002:33:2297-303.

33. Villapol S, Yaszemski AK, Logan TT, Sánchez-Lemus E, Saavedra JM, Symes AJ. Candesartan, an angiotensin II AT 1 -receptor blocker and PPAR- agonist, reduces lesion volume and improves motor and memory function after traumatic brain injury in mice. Neuropsychopharmacology. 2012;37:2817-29.

34. Wang J, Ho L, Chen L, Zhao Z, Zhao W, Qian X, et al. Valsartan lowers brain beta-amyloid protein levels and improves spatial learning in a mouse model of Alzheimer disease. J Clin Investig. 2007;117:3393-402. 
35. Zhou J, Ando H, Macova M, Dou J, Saavedra JM. Angiotensin II AT(1) receptor blockade abolishes brain microvascular inflammation and heat shock protein responses in hypertensive rats. J Cereb Blood Flow Metab. 2005;25:878-86.

36. Dandona P, Kumar V, Aljada A, Ghanim H, Syed T, Hofmayer D, et al. Angiotensin II receptor blocker valsartan suppresses reactive oxygen species generation in leukocytes, nuclear factor-kappa B, in mononuclear cells of normal subjects: evidence of an anti-inflammatory action. J Clin Endocrinol Metab. 2003;88:4496-501.

37. Miyoshi M, Miyano K, Moriyama N, Taniguchi M, Watanabe T. Angiotensin type 1 receptor antagonist inhibits lipopolysaccharide-induced stimulation of rat microglial cells by suppressing nuclear factor $\mathrm{kB}$ and activator protein1 activation. Eur J Neurosci. 2008;27:343-51.

38. Fogari R, Mugellini A, Zoppi A, Marasi G, Pasotti C, Poletti L, et al. Effects of valsartan compared with enalapril on blood pressure and cognitive function in elderly patients with essential hypertension. Eur J Clin Pharmacol. 2004:59:863-8.

39. Anderson C. More indirect evidence of potential neuroprotective benefits of angiotensin receptor blockers. J Hypertens. 2010;28:429.

40. Davies NM, Kehoe PG, Ben-Shlomo Y, Martin RM. Associations of antihypertensive treatments with Alzheimer's disease, vascular dementia, and other dementias. J Alzheimer's Dis. 2011;26:699-708.

41. Li NC, Lee A, Whitmer RA, Kivipelto M, Lawler E, Kazis LE, et al. Use of angiotensin receptor blockers and risk of dementia in a predominantly male population: prospective cohort analysis. BMJ. 2010;340:b5465.

42. Contestabile A. Cerebellar granule cells as a model to study mechanisms of neuronal apoptosis or survival in vivo and in vitro. Cerebellum. 2002;1:41-55.

43. Krämer D, Minichiello L. Cell culture of primary cerebellar granule cells. Methods Mol Biol. 2010;633:233-9.

44. Morkuniene $R$, Cizas $P$, Jankeviciute $S$, Petrolis $R$, Arandarcikaite $O$, Krisciukaitis $A$, et al. Small Aß1-42 oligomer-induced membrane depolarization of neuronal and microglial cells: role of $\mathrm{N}$-methyl-D-aspartate receptors. J Neurosci Res. 2015;93:475-86.

45. Bobba A, Amadoro G, Azzariti A, Pizzuto R, Atlante A. Extracellular ADP prevents neuronal apoptosis via activation of cell antioxidant enzymes and protection of mitochondrial ANT-1. Biochim Biophys Acta. 2014;1837:1338-49.

46. Vázquez de la Torre A, Junyent F, Folch J, Pelegrí C, Vilaplana J, Auladell C, et al. PI3K/AKT inhibition induces apoptosis through p38 activation in neurons. Pharmacol Res. 2013;70:116-25.

47. Mootha VK, Lindgren CM, Eriksson K-F, Subramanian A, Sihag S, Lehar J, et al. PGC-1 -responsive genes involved in oxidative phosphorylation are coordinately downregulated in human diabetes. Nat Genet. 2003;34:267-73.

48. Subramanian A, Tamayo P, Mootha VK, Mukherjee S, Ebert BL, Gillette MA, et al. Gene set enrichment analysis: a knowledge-based approach for interpreting genome-wide expression profiles. Proc Natl Acad Sci U S A 2005;102:15545-50.

49. Gao XM, Margolis RL, Leeds P, Hough C, Post RM, Chuang DM. Carbamazepine induction of apoptosis in cultured cerebellar neurons: effects of N-methyl-D-aspartate, aurintricarboxylic acid and cycloheximide. Brain Res. 1995;703:63-71.

50. Lee HY, Greene LA, Mason CA, Manzini MC. Isolation and culture of postnatal mouse cerebellar granule neuron progenitor cells and neurons. J Vis Exp. 2009;23. doi:10.3791/990.

51. Delacrétaz E, Nussberger J, Biollaz J, Waeber B, Brunner HR. Characterization of the angiotensin II receptor antagonist TCV-116 in healthy volunteers. Hypertension. 1995;25:14-21.

52. Gene Set enrichment analysis (GSEA). http://www.broadinstitute.org/gsea/. Accessed May 2015

53. Kyoto Encyclopedia of Genes and Genomes (KEGG). http://www.genome.jp/ kegg/. Accessed May 2015

54. Biocarta. http://cgap.nci.nih.gov/Pathways/BioCarta_Pathways. Accessed on May 2015.

55. Reactome. http://www.reactome.org/pages/documentation/citingreactome-publications/. Accessed on May 2015.

56. Broad Molecular Signatures Database v5.0 (MSigDB). http://www. broadinstitute.org/gsea/. Accessed on May 2015.

57. Gene Omnibus database. http://www.ncbi.nlm.nih.gov/geo/. Accessed on May 2015.

58. Ingenuity pathway analysis. http://www.ingenuity.com. Accessed on May 2015
59. Blalock EM, Geddes JW, Chen KC, Porter NM, Markesbery WR, Landfield PW. Alzheimer's disease: microarray correlation analyses reveal major transcriptional and tumor suppressor responses. Proc Natl Acad Sci U S A. 2004;101:2173-8.

60. Blair LJ, Nordhues BA, Hill SE, Scaglione KM, O'Leary 3rd JC, Fontaine SN, et al. Accelerated neurodegeneration through chaperone-mediated oligomerization of tau. J Clin Invest. 2013;123:4158-69.

61. Hokama M, Oka S, Leon J, Ninomiya T, Honda H, Sasaki K, et al. Altered expression of diabetes-related genes in Alzheimer's disease brains: the Hisayama study. Cereb Cortex. 2014;24:2476-688.

62. Harris LW, Wayland M, Lan M, Ryan M, Giger T, Lockstone H, et al. The cerebral microvasculature in schizophrenia: a laser capture microdissection study. PLoS One. 2008;3:e3964.

63. Giger T, Khaitovich P, Somel M, Lorenc A, Lizano E, Harris LW, et al. Evolution of neuronal and endothelial transcriptomes in primates. Genome Biol Evol. 2010;12:284-92.

64. AbdAlla S, Langer A, Fu X, Quitterer U. ACE inhibition with captopril retards the development of signs of neurodegeneration in an animal model of Alzheimer's disease. Int J Mol Sci. 2013;14:16917-42.

65. Deuss M, Reiss K, Hartmann D. Part-time alpha-secretases: the functional biology of ADAM 9, 10 and 17. Curr Alzheimer Res. 2008;5:187-201.

66. Asai M, Hattori C, Szabó B, Sasagawa N, Maruyama K, Tanuma S, et al. Putative function of ADAM9, ADAM10, and ADAM17 as APP alpha-secretase. Biochem Biophys Res Commun. 2003;301:231-5.

67. Meng P, Yoshida H, Matsumiya T, Imaizumi T, Tanji K, Xing F, et al. Carnosic acid suppresses the production of amyloid- $\beta 1-42$ by inducing the metalloprotease gene TACE/ADAM17 in SH-SY5Y human neuroblastoma cells. Neurosci Res. 2013;75:94-102.

68. Lane RM, Farlow MR. Lipid homeostasis and apolipoprotein E in the development and progression of Alzheimer's disease. J Lipid Res. 2005;46:949-68.

69. Zhou S, Wu H, Zeng C, Xiong X, Tang S, Tang Z, et al. Apolipoprotein E protects astrocytes from hypoxia and glutamate-induced apoptosis. FEBS Lett. 2013;587:254-8.

70. Lee Y, Aono M, Laskowitz D, Warner DS, Pearlstein RD. Apolipoprotein E protects against oxidative stress in mixed neuronal-glial cell cultures by reducing glutamate toxicity. Neurochem Int. 2004;44:107-18.

71. Liu L, Aboud O, Jones RA, Mrak RE, Griffin WS, Barger SW. Apolipoprotein E expression is elevated by interleukin 1 and other interleukin 1-induced factors. J Neuroinflammation. 2011;8:175. doi:10.1186/1742-2094-8-175.

72. Hoe HS, Harris DC, Rebeck GW. Multiple pathways of apolipoprotein E signaling in primary neurons. J Neurochem. 2005;93:145-55.

73. Nelson L, Gard P, Tabet N. Hypertension and inflammation in Alzheimer's disease: close partners in disease development and progression. J Alzheimers Dis. 2014;41:331-43.

74. Perry VH, Holmes C. Microglial priming in neurodegenerative disease. Nat Rev Neurol. 2014;10:217-24.

75. Medeiros R, Figueiredo CP, Pandolfo P, Duarte FS, Prediger RD, Passos GF, et al. The role of TNF-alpha signaling pathway on COX-2 upregulation and cognitive decline induced by beta-amyloid peptide. Behav Brain Res. 2010;209:165-73.

76. Yu X, Wang LN, Du QM, Ma L, Chen L, You R, et al. Akebia Saponin D attenuates amyloid $\beta$-induced cognitive deficits and inflammatory response in rats: involvement of Akt/NF-kB pathway. Behav Brain Res. 2012;235:200-9.

77. Ewers M, Mielke MM, Hampel H. Blood-based biomarkers of microvascular pathology in Alzheimer's disease. Exp Gerontol. 2010;45:75-9.

78. Sintes J, Romero X, de Salort J, Terhorst C, Engel P. Mouse CD84 is a pan-leukocyte cell-surface molecule that modulates LPS-induced cytokine secretion by macrophages. J Leukoc Biol. 2010;88:687-97.

79. Israelsson C, Bengtsson H, Lobell A, Nilsson LN, Kylberg A, Isaksson M, et al. Appearance of Cxcl10-expressing cell clusters is common for traumatic brain injury and neurodegenerative disorders. Eur J Neurosci. 2010;31:852-63.

80. Wang F, Liu H, Shen $X, A o H$, Moore $N$, Gao L, et al. The combined treatment of amyloid- $\beta 1$-42-stimulated bone marrow-derived dendritic cells plus splenocytes from young mice prevents the development of Alzheimer's disease in APPswe/PSENIdE9 mice. Neurobiol Aging. 2015:36:111-22.

81. Skeie JM, Fingert JH, Russell SR, Stone EM, Mullins RF. Complement component C5a activates ICAM-1 expression on human choroidal endothelial cells. Invest Ophthalmol Vis Sci. 2010;51:5336-42. 
82. Abel S, Hundhausen C, Mentlein R, Schulte A, Berkhout T, Broadway N, et al. The transmembrane CXC-chemokine ligand 16 is induced by IFN-gamma and TNF-alpha and shed by the activity of the disintegrin-like metalloproteinase ADAM10. J Immunol. 2004;172:6362-72.

83. Chang MS, McNinch J, Basu R, Simonet S. Cloning and characterization of the human neutrophil-activating peptide (ENA-78) gene. J Biol Chem. 1994;269:25277-82.

84. Goruppi S, lovanna JL. Stress-inducible protein p8 is involved in several physiological and pathological processes. J Biol Chem. 2010;285:1577-81.

85. Jin P, Choi DY, Hong JT. Inhibition of extracellular signal-regulated kinase activity improves cognitive function in Tg2576 mice. Clin Exp Pharmacol Physiol. 2012;39:852-7.

86. Chen CC, Liu HP, Chao M, Liang Y, Tsang NM, Huang HY, et al. NF-KBmediated transcriptional upregulation of TNFAIP2 by the Epstein-Barr virus oncoprotein, LMP1, promotes cell motility in nasopharyngeal carcinoma. Oncogene. 2014;33:3648-59.

87. Palmer JC, Barker R, Kehoe PG, Love S. Endothelin-1 is elevated in Alzheimer's disease and upregulated by amyloid- $\beta$. J Alzheimers Dis. 2012;29:853-61.

88. Oh J, Lee HJ, Song JH, Park SI, Kim H. Plasminogen activator inhibitor-1 as an early potential diagnostic marker for Alzheimer's disease. Exp Gerontol. 2014;60:87-91

89. Lehmann SM, Krüger C, Park B, Derkow K, Rosenberger K, Baumgart J, et al. An unconventional role for miRNA: let-7 activates Toll-like receptor 7 and causes neurodegeneration. Nat Neurosci. 2012;15:827-35.

90. Ben-Menachem-Zidon O, Ben-Menahem Y, Ben-Hur T, Yirmiya R. Intrahippocampal transplantation of neural precursor cells with transgenic overexpression of IL-1 receptor antagonist rescues memory and neurogenesis impairments in an Alzheimer's disease model. Neuropsychopharmacology. 2014;39:401-14.

91. Piantadosi CA, Withers CM, Bartz RR, MacGarvey NC, Fu P, Sweeney TE, et al. Heme oxygenase-1 couples activation of mitochondrial biogenesis to antiinflammatory cytokine expression. J Biol Chem. 2011;286:16374-85.

92. McArthur S, Cristante E, Paterno M, Christian H, Roncaroli F, Gillies GE, et al. Annexin A1: a central player in the anti-inflammatory and neuroprotective role of microglia. J Immunol. 2010;185:6317-28.

93. Lee HP, Pancholi N, Esposito L, Previll LA, Wang X, Zhu X, et al. Early induction of oxidative stress in mouse model of Alzheimer disease with reduced mitochondrial superoxide dismutase activity. PLoS One. 2012;7:e28033. doi:10.1371/journal.pone.0028033.

94. Cuenda A, Rousseau S. p38 MAP-kinases pathway regulation, function and role in human diseases. Biochim Biophys Acta. 2007;1773:1358-75.

95. Quintanilla RA, Orellana DI, González-Billault C, Maccioni RB. Interleukin-6 induces Alzheimer-type phosphorylation of tau protein by deregulating the cdk5/p35 pathway. Exp Cell Res. 2004;295:245-57.

96. Ashabi G, Alamdary SZ, Ramin M, Khodagholi F. Reduction of hippocampal apoptosis by intracerebroventricular administration of extracellular signalregulated protein kinase and/or p38 inhibitors in amyloid beta rat model of Alzheimer's disease: involvement of nuclear-related factor-2 and nuclear factor-kB. Basic Clin Pharmacol Toxicol. 2013;112:145-55.

97. Zhou Q, Wang M, Du Y, Zhang W, Bai M, Zhang Z, et al. Inhibition of c- Jun $\mathrm{N}$-terminal kinase activation reverses Alzheimer disease phenotypes in APPswe/PS1dE9 mice. Ann Neurol. 2015;77:637-54.

98. Ha JS, Sung HY, Lim HM, Kwon KS, Park SS. PI3K-ERK1/2 activation contributes to extracellular $\mathrm{H} 2 \mathrm{O} 2$ generation in amyloid $\beta$ toxicity. Neurosci Lett. 2012;526:112-7.

99. Wyss-Coray T, Lin C, Sanan DA, Mucke L, Masliah E. Chronic overproduction of transforming growth factor- $\beta 1$ by astrocytes promotes Alzheimer's disease-like microvascular degeneration in transgenic mice. Amer J Pathol. 2000;156:139-50

100. Frankfurt M, Luine $V$. The evolving role of dendritic spines and memory: interaction(s) with estradiol. Horm Behav. 2015. doi:10.1016/j.yhbeh.2015.05. 004.

101. Bian C, Zhu H, Zhao Y, Cai W, Zhang J. Intriguing roles of hippocampussynthesized $17 \beta$-estradiol in the modulation of hippocampal synaptic plasticity. J Mol Neurosci. 2014;54:271-81.

102. Petrone AB, Gatson JW, Simpkins JW, Reed MN. Non-feminizing estrogens: a novel neuroprotective therapy. Mol Cell Endocrinol. 2014;389:40-7.

103. ladecola C. The pathobiology of vascular dementia. Neuron. 2013;80:844-66.
104. Klohs J, Rudin M, Shimshek DR, Beckmann N. Imaging of cerebrovascular pathology in animal models of Alzheimer's disease. Front Aging Neurosci. 2014;6:32. doi:10.3389/fnagi.2014.00032.

105. Lee CW, Shih YH, Kuo YM. Cerebrovascular pathology and amyloid plaque formation in Alzheimer's disease. Curr Alzheimer Res. 2014;11:4-10.

106. Lyros E, Bakogiannis C, Liu Y, Fassbender K. Molecular links between endothelial dysfunction and neurodegeneration in Alzheimer's disease. Curr Alzheimer Res. 2014;11:18-26.

107. Muresanu DF, Popa-Wagner A, Stan A, Buga AM, Popescu BO. The vascular component of Alzheimer's disease. Curr Neurovasc Res. 2014;11:168-76.

108. Wiesmann M, Kiliaan AJ, Claassen JA. Vascular aspects of cognitive impairment and dementia. J Cereb Blood Flow Metab. 2013;33:1696-706.

109. Mota SI, Costa RO, Ferreira IL, Santana I, Caldeira GL, Padovano C, et al. Oxidative stress involving changes in Nrf2 and ER stress in early stages of Alzheimer's disease. Biochim Biophys Acta. 2015;1852:1428-41.

110. Villapol S, Saavedra JM. Neuroprotective effects of angiotensin receptor blockers. Am J Hypertens. 2015;28:289-99.

111. Tian M, Zhu D, Xie W, Shi J. Central angiotensin II-induced Alzheimer-like tau phosphorylation in normal rat brains. FEBS Lett. 2012;586:3737-45. Erratum in FEBS Lett. 2013:587:818

112. Shindo T, Takasaki K, Uchida K, Onimura R, Kubota K, Uchida N, et al. Ameliorative effects of telmisartan on the inflammatory response and impaired spatial memory in a rat model of Alzheimer's disease incorporating additional cerebrovascular disease factors. Biol Pharm Bull. 2012;35:2141-7.

113. Zhao W, Wang J, Ho L, Ono K, Teplow DB, Pasinetti GM. Identification of antihypertensive drugs which inhibit amyloid-beta protein oligomerization. J Alzheimers Dis. 2009;16:49-57.

114. Miners JS, Palmer JC, Tayler H, Palmer LE, Ashby E, Kehoe PG, et al. A degradation or cerebral perfusion? Divergent effects of multifunctional enzymes. Front Aging Neurosci. 2014;6:238. doi:10.3389/fnagi.2014.00238. eCollection2014.

115. Trenkwalder P. Potential for antihypertensive treatment with an AT(1)receptor blocker to reduce dementia in the elderly. J Hum Hypertens. 2002;16:S71-5.

116. Larrayoz IM, Pang T, Benicky J, Pavel J, Sánchez-Lemus E, Saavedra JM. Candesartan reduces the innate immune response to lipopolysaccharide in human monocytes. J Hypertens. 2009;27:2365-76.

117. Rouch L, Cestac P, Hanon O, Cool C, Helmer C, Bouhanick B, et al. Antihypertensive drugs, prevention of cognitive decline and dementia: a systematic review of observational studies, randomized controlled trials and meta-analyses, with discussion of potential mechanisms. CNS Drugs. 2015. [Epub ahead of print] doi:10.1007/s 40263-015-0230-6.

118. Igase M, Kohara K, Miki T. The association between hypertension and dementia in the elderly. Int J Hypertens. 2012;320648. doi:10.1155/2012/ 320648

119. Ashby EL, Kehoe PG. Current status of renin-aldosterone angiotensin system-targeting anti-hypertensive drugs as therapeutic options for Alzheimer's disease. Expert Opin Investig Drugs. 2013;22:1229-42.

120. Hajjar I, Hart M, Milberg W, Novak V, Lipsitz L. The rationale and design of the antihypertensives and vascular, endothelial, and cognitive function (AVEC) trial in elderly hypertensives with early cognitive impairment: role of the renin angiotensin system inhibition. BMC Geriatr. 2009;9:48.

121. Wu X, Kihara T, Hongo H, Akaike A, Niidome T, Sugimoto H. Angiotensin receptor type 1 antagonists protect against neuronal injury induced by oxygen-glucose depletion. Br J Pharmacol. 2010;161:33-50.

\section{Submit your next manuscript to BioMed Central and we will help you at every step:}

- We accept pre-submission inquiries

- Our selector tool helps you to find the most relevant journal

- We provide round the clock customer support

- Convenient online submission

- Thorough peer review

- Inclusion in PubMed and all major indexing services

- Maximum visibility for your research

Submit your manuscript at www.biomedcentral.com/submit 